OPEN ACCESS

Edited by:

Merce Pallas,

University of Barcelona, Spain

Reviewed by:

Albert Rizvanov,

Kazan Federal University, Russia

Consuelo Morgado-Valle,

Universidad Veracruzana, Mexico

*Correspondence:

Alejandro A. Canales-Aguirre acanales@ciatej.mx

Received: 06 March 2018

Accepted: 30 August 2018

Published: 24 September 2018

Citation:

Reza-Zaldivar EE,

Hernández-Sapiéns MA, Minjarez B, Gutiérrez-Mercado YK,

Márquez-Aguirre AL and Canales-Aguirre AA (2018) Potential Effects of MSC-Derived Exosomes in

Neuroplasticity in

Alzheimer's Disease.

Front. Cell. Neurosci. 12:317.

doi: 10.3389/fncel.2018.00317

\section{Potential Effects of MSC-Derived Exosomes in Neuroplasticity in Alzheimer's Disease}

\author{
Edwin E. Reza-Zaldivar ${ }^{1}$, Mercedes A. Hernández-Sapiéns ${ }^{1}$, Benito Minjarez ${ }^{2}$, \\ Yanet K. Gutiérrez-Mercado ${ }^{1}$, Ana L. Márquez-Aguirre ${ }^{1}$ and Alejandro A. \\ Canales-Aguirre ${ }^{1,3 *}$
}

'Unidad de Evaluación Preclínica, Biotecnología Médica y Farmacéutica, CONACYT Centro de Investigación y Asistencia en Tecnología y Diseño del Estado de Jalisco (CIATEJ), Guadalajara, Mexico, ${ }^{2}$ Centro Universitario de Ciencias Biológicas y Agropecuarias (CUCBA), Universidad de Guadalajara, Guadalajara, Mexico, ${ }^{3}$ Profesor del programa de Maestría en Ciencias de la Salud Ambiental, Centro Universitario de Ciencias Biológicas y Agropecuarias (CUCBA), Universidad de Guadalajara, Guadalajara, Mexico

Alzheimer's disease (AD) is the most common type of dementia affecting regions of the central nervous system that exhibit synaptic plasticity and are involved in higher brain functions such as learning and memory. $A D$ is characterized by progressive cognitive dysfunction, memory loss and behavioral disturbances of synaptic plasticity and energy metabolism. Cell therapy has emerged as an alternative treatment of AD. The use of adult stem cells, such as neural stem cells and Mesenchymal Stem Cells (MSCs) from bone marrow and adipose tissue, have the potential to decrease cognitive deficits, possibly by reducing neuronal loss through blocking apoptosis, increasing neurogenesis, synaptogenesis and angiogenesis. These processes are mediated primarily by the secretion of many growth factors, anti-inflammatory proteins, membrane receptors, microRNAs (miRNA) and exosomes. Exosomes encapsulate and transfer several functional molecules like proteins, lipids and regulatory RNA which can modify cell metabolism. In the proteomic characterization of the content of MSC-derived exosomes, more than 730 proteins have been identified, some of which are specific cell type markers and others are involved in the regulation of binding and fusion of exosomes with adjacent cells. Furthermore, some factors were found that promote the recruitment, proliferation and differentiation of other cells like neural stem cells. Moreover, within exosomal cargo, a wide range of miRNAs were found, which can control functions related to neural remodeling as well as angiogenic and neurogenic processes. Taking this into consideration, the use of exosomes could be part of a strategy to promote neuroplasticity, improve cognitive impairment and neural replacement in AD. In this review, we describe how exosomes are involved in $A D$ pathology and discuss the therapeutic potential of MSC-derived exosomes mediated by miRNA and protein cargo.

Keywords: exosomes, Alzheimer's disease, neuroplasticity, exosomal cargo, proteomics, miRNA

\section{INTRODUCTION}

Alzheimer's disease $(\mathrm{AD})$ is characterized by the progressive deposition of $\beta$-amyloid $(\mathrm{A} \beta$ ) around neurons and the intracellular accumulation of neurofibrillary tangles (NFT) of hyperphosphorylated tau, mainly in areas implicated in memory and learning, such as the prefrontal cortex and hippocampus. In advanced stages of the disease, aggregates of $A \beta$ are present in 
motor areas, cerebrospinal fluid, as well as in eyes and neuromuscular joints (Reiss et al., 2018).

Presently there is no effective treatment for $\mathrm{AD}$ hence, stem cell therapy has been proposed to be a promising therapeutic option for this neurological disorder. Cell therapies for brain restoration generally target multiple cells of the brain parenchyma such as endothelial cells, neural stem cells (also named neural progenitors) and oligodendrocyte precursor cells. The interaction between the administered cells and resident cells promote neuroplastic events such angiogenesis stimulation, neurogenesis and axonal remodeling, result in a neurological recovery (Xin et al., 2017a; Xiong et al., 2017).

Several studies have demonstrated the effectiveness of Mesenchymal Stem Cells (MSCs) treatment in several neurodegenerative diseases (Wei et al., 2013). These cells have typical stem cell characteristics like the potential to differentiate into multiple cell lineages under different physiological conditions, including the ability to selectively migrate towards damage sites (homing) and interact with brain parenchyma cells. This interaction stimulate the production of neurotrophins such as vascular endothelial growth factor (VEGF), hepatocyte growth factor (HGF), nerve growth factor (NGF), brain-derived neurotrophic factor (BDNF) and neurotrophin-3 (Li et al., 2002; Kurozumi et al., 2004; Kim et al., 2010; Matthay et al., 2017) which increase neuritic development, promote neurorestoration and neurological recovery (Xiong et al., 2017; Harting et al., 2018).

Among the main functions of MSCs are their ability to limit inflammation environments through the release of soluble factors such as HGF, prostaglandin E2, transforming growth factor $\beta 1$, indoleamine 2,3 dioxygenase, interleukin 10 and nitric oxide. This immunomodulatory environment allows the expression of growth factors, high immunomodulatory protein secretion and the enhancement of endogenous cellular repair processes (Nguyen et al., 2013; Phinney and Pittenger, 2017).

A central hypothesis has been proposed, in which MSCs are implied to exert a dynamic homeostatic response that supports tissue preservation as well as function recovery (Harting et al., 2018). The main mechanism by which MSCs mediate this activity is not the cellular implant and its subsequent differentiation, but the paracrine activity of the secretome (Nakano et al., 2016; Yang Y. et al., 2017). This phenomenon was demonstrated in studies where conditioned medium of MSCs was administered and therapeutic effects similar to those already reported for MSCs were produced in different animal models of diseases (Timmers et al., 2007; Mitsialis and Kourembanas, 2016). A subsequent fractionation of this conditioned medium was performed and an active component of approximately 50-150 nm was found. Biophysical studies categorized these compounds as exosomes (Lai et al., 2010; Phinney and Pittenger, 2017). Consequently, it was established that one of the critical parameters that regulate the paracrine activity of MSC is the generation of exosomes (Drommelschmidt et al., 2017; Phinney and Pittenger, 2017). Therefore, exosomes may be a therapeutic option in the treatment of $\mathrm{AD}$ because they exert therapeutic effects like MSCs.

\section{Biogenesis of Exosomes}

Exosomes are small (30-150 nm diameter) membrane-enclosed vesicles of endosomal origin, released by a variety of cell types, capable of transferring biologically active macromolecules, such as proteins, lipids and RNA, to other cells (Bang and Thum, 2012). Exosomes are originated as intraluminal vesicles within the multivesicular bodies (MVB) by inward budding of the late endosomal membrane (Colombo et al., 2014). The Endosomal Sorting Complex Required for Transport (ESCRT) machinery is important in this process. ESCRT consist of approximately 20 proteins that assemble four different complexes; ESCRT0, -I, -II, -III and the associated AAA ATPase vacuolar protein sorting 34 (Vps4) complex (Henne et al., 2013). ESCRT-0 recognizes and sequesters ubiquitylated proteins in the endosomal membrane, ESCRT-I and -II are responsible for membrane budding as well as recruiting of ESCRT-III that finally drive vesicle scission (Hurley and Hanson, 2010). The dissociation and recycling of the ESCRTs require the AAA ATPase Vps4 complex. Transport of MVB towards plasma membrane depends on interaction with the cytoskeleton, this interaction is mediated mainly by Rab GTPases and SNARE proteins, although precise mechanism of action in this process is not known (Ostrowski et al., 2009; Beer and Wehman, 2017). MVB subsequently fuse with the plasma membrane and release those intraluminal vesicles such as exosomes (Camacho et al., 2013; Abels and Breakefield, 2016). Some studies also suggest that MVB biogenesis can occur without ESCRTs. It has been shown that despite simultaneously silencing key subunits of all four ESCRTs, intraluminal vesicles are still formed in MVB, indicating the presence of a mechanism independent of ESCRT (Stuffers et al., 2009). Tetraspanins (Escola et al., 1998) and lipids (mainly ceramide; Trajkovic et al., 2008) could be essential players in exosome biogenesis due to the formation of microdomains that coalescence into larger domains that promote membrane budding.

As mentioned above, exosomes contain different proteins, lipids and nucleic acids (DNA, mRNA, microRNAs (miRNA), lncRNA), however, determining the exact composition and content of the exosomal content (cargo) produced by different cell types is hard to establish due to differences in the conditions which the cells are found. It should be mentioned that cellular homeostasis is an important factor that controls exosome cargo and secretion, therefore the exosomes will present characteristics that reflect its cellular origin (de Jong et al., 2012; Harting et al., 2018). Mechanisms for sorting cargo molecules into exosomes are still poorly understood. However, the ubiquitination is considered the main sorting signal for protein cargo entry into exosomes. Ubiquitinated proteins are recognized by receptors such as ESCRT subunits responsible for binding and directing cargo towards intraluminal vesicles (Piper and Katzmann, 2007). Usually these vesicles contain proteins that are involved in its biogenesis mechanisms, for example, ESCRT system components such as tetraspanins CD63, CD81 and CD9, as well as ALIX, TSG10, likewise proteins associated with their secretion as RAB27A, RAB11 and ARF6 (Wu et al., 2015; Abels and Breakefield, 2016). There are different pathways for miRNA sorting, which include: (I) neutral 
sphingomyelinase 2 pathway demonstrated by Kosaka et al. (2010), in where they found that overexpression of neutral sphingomyelinase 2 increased the amount of miRNA into exosomes, while its chemical inhibition reduced the number of miRNAs; (II) the miRNA motif and sumoylated heterogeneous nuclear ribonucleoproteins (hnRNPs) pathway reported by Villarroya-Beltri et al. (2013), identified a short sequence motifs in miRNAs (GGAG) in the portion $3^{\prime}$ that is recognized by exosomal sumoylated hnRNPs, this hnRNP-miRNA binding control the miRNA loading into exosomes; (III) the miRNA induced silencing complex (miRSC) pathway. Components of miRSC include miRNA, miRNA repressible mRNA, and proteins GW182 and AGO2; Guduric-Fuchs et al. (2012) discovered that knockout of AGO2 decreases the abundance of miRNA exported by exosomes. Besides AGO2, others components of miRSC like GW182 were found to be colocalized with MVB (Guduric-Fuchs et al., 2012). Despite this evidence of exosomal cargo sorting, the underlying mechanisms remain unclear.

Concerning lipid composition of the exosomal membrane, there are some lipids such as sphingomyelin, cholesterol, ganglioside GM3, phosphatidylserine and ceramide that form lipid raft domains that are more abundant in the exosomal membrane than in the cell of origin (Angeloni et al., 2016). In contrast, phosphatidylcholine and diacylglycerol are scarce in the membrane of exosomes compared to the cell membrane (Abels and Breakefield, 2016).

\section{Exosomes as Intercellular Communication Mediators}

There is evidence suggesting that exosomes are internalized into recipient cells (Mulcahy et al., 2014). However, elucidation of the mechanisms of exosome targeting and uptake by recipient cells remains an important challenge. Exosomes could bear combinations of ligands that would engage different cell-surface receptors simultaneously, therefore different mechanisms have been proposed by which a cell can interact and uptake these nanovesicles. This communication could be through membrane receptors and the subsequent exosome membrane fusion with the cell membrane to exchange proteins and cytosol components. An other mechanism is through endocytosis, among which are clathrin-mediated endocytosis, caveolinmediated endocytosis (Svensson et al., 2013), phagocytosis mediated mainly by phosphatidylserine, and micropinocytosis. The uptake mechanism used may depend on proteins and glycoproteins found on the surface of both the nanovesicle and the target cell.

Different studies establish that exosomes are mediators of intercellular communication, since they reach biological fluids such as blood, cerebrospinal fluid and urine among others, and act as paracrine messengers through the transference of bioactive lipids, mRNAs, miRNA, lncRNAs, and can also transfer genomic DNA and mitochondrial DNA and different proteins (Kalra et al., 2012; Keerthikumar et al., 2016). This transference of bioactive molecules establishing cell-cell communication processes can in an epigenetic way, alter the activity of the cells both in physiological and pathological conditions (Xiong et al., 2017; Harting et al., 2018).

Interestingly, the evidence shows that exosomes are released more under pathological conditions (Cheng et al., 2017). In this way, the most studied pathogenic components that use exosomes as infection route are the prion proteins (Vella et al., 2008), responsible for transmissible neurodegenerative diseases such as bovine spongiform encephalopathy and $\alpha$-synuclein (Emmanouilidou et al., 2010), involved in Parkinson's disease pathology. Prion diseases are fatal neurodegenerative disorders associated with the conversion of the cellular prion protein into the scrapie prion protein, an abnormal conformational state that tends to form amyloid deposits in brain tissue leading to dementia (Vingtdeux et al., 2012). On the other hand, exosomes released from cells that have an overproduction of $\alpha$-synuclein can transfer this protein to normal cells and promote the overproduction by alterations in the ESCRT system that result in an increased exocytosis of exosomes with $\alpha$-synuclein (Spencer et al., 2016). In AD, it has been proposed that exosomes have a key pathological function in the progression of the disease, and are involved in $\mathrm{A} \beta$ and tau dissemination, since an accumulation of exosomes has been found in amyloid plaques (Rajendran et al., 2006) and hyperphosphorylated tau tangles (Saman et al., 2012, 2014; Levy, 2017).

\section{ALZHEIMER'S DISEASE}

$\mathrm{AD}$ is the most common neurodegenerative disease characterized by neuron loss and impairment of memory, cognition and functions of daily living. In many cases, death results from the loss of fine motor skills and incapacitation (Koelsch, 2017; Mroczko et al., 2018). The main pathological markers of AD are the accumulation of $A \beta$ plaques and the formation of NFT, composed of hyperphosphorylated tau protein (Eitan et al., 2016). In early stages, these pathological changes are primarily localized within the medial temporal lobe and are spread through the neocortex (Braak and Braak, 1996).

Accumulation of $A \beta$ in oligomers is one of the earliest events in the disease process, occurring 10-20 years prior to the onset of memory loss and other clinical symptoms (Reiman et al., 2012). Amyloid plaque formation are the result of $A \beta$ peptides deposition that takes place in early endosomes, this process involves sequential hydrolysis of the amyloid precursor protein (APP) by $\beta$ and $\gamma$-secretases (Rajendran et al., 2006). The $\beta$-site APP cleaving enzyme 1 (BACE1) is a transmembrane type I aspartyl protease that is located in endosomes as an immature precursor protein, and later in lysosomes and Golgi complex as a mature protein that catalyzes the initial amyloidogenic cleavage at $\beta$-site of APP while the membraneassociated 99 amino acid carboxyl-terminal fragment $\beta$ remains (Munro et al., 2016; Yan et al., 2016). The $\gamma$-secretase has been identified as a multimeric protein complex containing presenilin 1, presenilin 2 associated with nicastrin, Aph-1 and Pen-2. The carboxyl-terminal fragment $\beta$ is cleaved by $\gamma$-secretase releasing $\mathrm{A} \beta$ peptides (Sharples et al., 2008). The A $\beta$ peptides released have pathophysiological impacts on synaptic function through 
inhibition of transmission of the synaptic signal leading neuronal death (Mroczko et al., 2018).

On the other hand, NFTs are formed by massive accumulations of abnormal insoluble polymers, referred to as paired helical filaments (Wischik et al., 1985, 1988). The main structural component of this filaments is tau, a microtubuleassociated protein (Kosik et al., 1986). The physiological function of tau is to stabilize microtubules in the cell cytoskeleton, an activity regulated by its phosphorylation (Grundke-Iqbal et al., 1986). It has been suggested that abnormal phosphorylation is an early molecular event that may lead to a sequence of structural changes in the tau molecule, such as conformational changes like truncations (Luna-Muñoz et al., 2007) and is thought that hyperphosphorylation and its aggregation are related to the disassembling of neuronal microtubules, that consequently affect axonal transport and result in cell death (Stoothoff and Johnson, 2005). Hyperphosphorylation of tau primarily occurs at Ser-Pro or Thr-Pro motifs, suggesting that proline-directed kinases such as the MAPK, GSK3 $\beta$ and CDK5 are directly involved (Mandelkow et al., 1992; Baumann et al., 1993; Greenberg et al., 1994). Other kinases are also able to modify the tau molecule, including CAMK, PKA and PKC (Correas et al., 1992; Scott et al., 1993; Ghosh and Giese, 2015).

Dissemination of $A \beta$ and tau has been suggested to be mediated through release of extracellular vesicles (EVs; Nath et al., 2012). EV are small membrane vesicles which result from the budding of the plasma membrane as microvesicles (also called ectosomes) or from the exocytosis of MVB as exosomes. EV is considered one of the distant extracellular communication agents due to its capacity to carry and deliver different types of components to target cells (Zhang and Yang, 2018). A relationship between $\mathrm{EV}$ and progression of $\mathrm{AD}$ has been proposed because most of the $A \beta$ and tau oligomers are colocalized with late endosome/lysosome markers, mainly MVB (Nath et al., 2012; Joshi et al., 2015). During disease progression, both these histopathological hallmarks extend throughout the brain with characteristic patterns reaching limbic and association areas (Cho et al., 2016).

\section{Role of Exosomes in Alzheimer's Disease}

Although the origin of the disease remains unknown, several investigations have postulated prion-like mechanisms in $\mathrm{AD}$ progression and dissemination, including direct cell communication through gap junctions, synaptic transmission and exacerbated paracrine signaling due to alterations of endosomal/lysosomal secretion system, in which exosomes play a fundamental role in the distribution of neuropathological components between neuronal cells (Gauthier et al., 2017; Xiao et al., 2017; Laulagnier et al., 2018).

Subcellular location of neuronal $A \beta$ was identified using immunoelectron microscopy by Takahashi et al. (2002), they found that $A \beta 42$ is localized predominantly within MVB of the neurons. Accumulation of $A \beta$ inside neurons is prevented by autophagy, an event occurring in the endosomal/lysosomal system where $A \beta$ within endosomes are destroyed by lysosomes (Mizushima and Komatsu, 2011). A key regulator of this system is phosphatidylinositol-3-phosphate (PI3P), a phospholipid synthesized mainly by class III PI3-kinase Vps34 (Jaber et al., 2016). Miranda et al. (2018) showed that disruption of neuronal Vps34 (a retromer complex component) function impairs autophagy, lysosomal degradation as well as lipid metabolism. This promotes the secretion of unique exosomes enriched with undigested lysosomal substrates, including $A B$, APP and the enzymes that process APP in an amyloidogenic way (Malm et al., 2016). In addition, this accumulation increases with aging and it is associated with abnormal synaptic morphology (Takahashi et al., 2002). Overall, inhibiting neutral sphingomyelinase 2, a key regulatory enzyme in ceramide synthesis and exosome biogenesis, reduced the number of exosomes in the brain and serum and further reduced $\mathrm{A} \beta$ plaque load in $5 \times \mathrm{FAD}$ mice (Dinkins et al., 2016). These observations suggest that MVB is essential for APP metabolism and A $\beta$ secretion (Takahashi et al., 2002; Joshi et al., 2015). Furthermore, other studies demonstrated that transference of damaged neuronal cell-derived exosomes with APP, $\gamma / \beta$ secretases, A $\beta$ peptides, APP-CTF, ubiquitins, modified ubiquitin ligases and tau protein to adjacent neurons can lead to AD propagation (Chen et al., 2017; Yuyama and Igarashi, 2017; Zheng et al., 2017; Miranda et al., 2018).

An interactome analysis demonstrated that inhibition of $\gamma$-secretase activity results in a significant increase of exosomes enriched with APP-CTF suggesting the association of $\gamma$-secretase in exosome membrane. Also, it was shown that exosomes tetraspanins CD9 and CD81 interact with the $\gamma$-secretase complex regulating their activity in a positive way. Using neutralizing antibodies against CD9 and CD81 result in the disruption of $A \beta$ generation and lead to an accumulation of the APP-CTF (Wakabayashi et al., 2009). Likewise, tetraspanin 6 enrichment in exosomal membrane allows the accumulation of A $\beta$, CTF-APP and BACE1 in exosomes, and independently of ESCRT, increases biogenesis of exosomes and secretion of this type of cargo, as well as inhibits the degradation of these nanovesicles by the lysosomal system (Guix et al., 2017). Thereby, these studies suggest the involvement of the tetraspanin web protein in the up and down regulation of $A \beta$ generation.

It has been reported that the endosomal localization of BACE1 is regulated by the ACG sequence and the retromer, a multiprotein complex required for the recycling of transmembrane proteins from the endosomes to the trans-Golgi network (Tan and Evin, 2012). Kizuka et al. (2015) showed that BACE1 is modified with bisecting $\mathrm{N}$-acetylglucosamine, a sugar modification highly expressed in the brain of AD patients, by GnT-III. They reported that lack of this modification directs BACE1 to late/lysosomes where it is less colocalized with APP, however, the glycan modification is protective for lysosomal degradation.

Furthermore, the $A \beta$ peptides already present in extracellular space can interact with the exosomal membrane through their glycosphingolipids and the cellular prion protein $\left(\mathrm{PrP}^{\mathrm{C}}\right)$, forming aggregates of $\mathrm{A} \beta$ (Rajendran et al., 2006; Zappulli et al., 2016; Yuyama and Igarashi, 2017; Zheng et al., 2017). This was demonstrated in the histological analysis performed in brains of $\mathrm{AD}$ patients were an enrichment of exosomal markers Alix and flotillin-1 was found around neuritic plaques; this suggested that exosomes function as nucleation centers 
for amyloid plaque formation (Xiao et al., 2017). A recent publication by Falker et al. (2016) showed that $\mathrm{PrP}^{\mathrm{C}}$ is highly enriched on exosomes membranes and distinct $\mathrm{A} \beta$ oligomers bind $\operatorname{PrP}^{\mathrm{C}}$ with high affinity via its flexible $\mathrm{N}$-terminus. This bind drives $A \beta$ fibrillation and may be involved in the extracellular deposition of $\mathrm{A} \beta$. However, there is a debate about if $\operatorname{PrP}^{\mathrm{C}}$ is required for $A \beta$-mediated synaptotoxicity and suppression of long-term potentiation (Lauren et al., 2009; Kessels et al., 2010).

On the other hand, it has been proposed that the spread of tau can occur through neuronal synaptic connections, but the mechanism underlying this process remains unknown (Wang Y. et al., 2017). However, it also has been reported that monomers and oligomers of tau hyperphosphorylated are encapsulated within the exosomes (Shi et al., 2016), which are then transferred through synaptic contact with other neurons, and like the exosomes that interact with $\mathrm{A} \beta$, can promote nucleation centers for hyperphosphorylated tau aggregation (Saman et al., 2012, 2014).

In addition to neural cell interaction, exosomes from damaged cells also interact with glial cells. Consequently, astrocytes not only fail to support neurons but also generate a toxic environment that is detrimental to neurons and astrocytes themselves through promoting secondary apoptosis of adjacent cells (Wang et al., 2012). Wang et al. (2012) found that the astrocytic-mediated apoptosis is associated with the secretion of PAR-4/ceramide containing exosomes in the adjacent cells even if they were not exposed to $A \beta$. It has been demonstrated that astrocytes tend to interact more with exosomes and accumulate large amounts of $\mathrm{A} \beta 42$ protofibers, subsequently, this storage results in endosomal/lysosomal system alterations which induce exosome secretion with a neurotoxic cargo (Nikitidou et al., 2017). Astrocyte-derived exosomes of patients with AD had up to 20 -fold higher concentrations of $\beta / \gamma$-secretase and sAPP $\beta$ than neuron-derived exosomes (Goetzl et al., 2016). Moreover, Chiarini et al., 2017 presented evidence showing that tau and its hyperphosphorylated form are expressed by untransformed astrocytes in culture exposed to $\mathrm{A} \beta$, the release is mediated by exosomes to the extracellular medium.

In addition, microglia also participates in the internalization of exosomes derived from damaged cells, Ikezu et al. (2016) found that microglia transduces tau aggregates into nearby neuronal cells via exosome secretion, tau aggregates propagate from cortical neurons to dentate granular cells and this propagation is sensitive to exosome inhibition or microglial depletion. In $\mathrm{AD}, \mathrm{A} \beta$ phagocytosis by microglia is one of the principal mechanisms for a level decrease of these peptides. Exosome phagocytosis is a process mediated by phosphatidylserine; as well as in apoptotic cells, exosomal phosphatidylserine is found in the outer layer of the membrane, so it can be recognized by microglia phosphatidylserine receptor (Yuyama and Igarashi, 2017). However, in AD, microglia activity is markedly diminished, therefore, when $\mathrm{A} \beta$ interacts with exosomes, it initiates the formation of large aggregates in the form of plaques (Zheng et al., 2017).

Since $\mathrm{AD}$ has a long asymptomatic latency period, many investigators are searching for biomarkers that can detect the disease early on, particularly in its pre-symptomatic and early stages. Different studies show that deregulation in miRNA expression and its traffic via exosomes has repercussions on $\mathrm{AD}$ pathogenesis (Lugli et al., 2015). miRNAs are endogenous, short, noncoding RNAs of 18-25 nucleotides which act as important post-transcriptional regulators of gene expression by binding with their target mRNA (Liu C. G. et al., 2014). Currently there are about 2,650 different miRNAs identified in all human tissues and only 34-40 miRNA are abundant in the brain (Jaber et al., 2017), among them, there are different miRNAs that bind specifically to key genes that determine the expression of APP and $\beta$-secretase, such as miR-193b, miR-101 and miR-29c respectively, these miRNAs negatively influence the generation of A $\beta$ (Lei et al., 2015; Chen et al., 2017). Nevertheless, it has been found that expression of these miRNAs decreased with AD progression (Liu C. G. et al., 2014). Lugli et al. (2015) performed an exosomal miRNAs analysis samples of people with $\mathrm{AD}$ and control people. They indicated that 20 miRNAs showed differential expression in $\mathrm{AD}$, and miR-342-3p, miR-141-3p, miR-342-5p, miR-23b-3p, miR-24-3p, miR-125b-5p and miR$152-3 p$ were selected as most predictive for AD group identity. Furthermore, miR-9, miR-125b, miR-191-5p, miR-181c and let$7 \mathrm{~g}-5 \mathrm{p}$ are thought to be the best candidates for early biomarkers (Trotta et al., 2018).

As mentioned above, defects in protein transport are closely related with neurodegeneration. In this context, it has been reported that genes like SEC22B and SEC63 which participate in protein transport and regulation of cell motion are downregulated by miR-206 in the $\mathrm{AD}$, the increase of this miRNA leads to a disequilibrium of proteostasis in the brain that could result in $A \beta$ accumulation (Zhao et al., 2016b).

On the other hand, it has been shown that the miR-132/miR212 cluster regulates tau expression. Smith et al. (2015) showed that miR-132/miR-212 deficiency in mice leads to increased tau expression, phosphorylation and aggregation, an effect associated with an autophagy dysfunction. Conversely, treatment of $\mathrm{AD}$ mice with miR-132/miR-212 restore, in part, memory dysfunction and tau metabolism.

Some miRNAs like miR-139 over express in $\mathrm{AD}$, this overexpression impairs the hippocampus-dependent learning and memory formation by targeting the cannabinoid receptor type 2 (Tang et al., 2017), a membrane marker of activated microglial cells, which triggers pathophysiological events involved in synaptic plasticity and neuroprotection but is also implicated in diverse roles in regulating memory, depending on memory types and brain areas (Li and Kim, 2016).

However, due to the high degree of heterogeneity in miRNAs, further in-depth investigation is required to provide easily identifiable biomarkers of $\mathrm{AD}$ that can be isolated from blood or its components. It is also important to consider is the possibility of using miRNA approaches like the modulation of these miRNAs for the treatment of AD.

\section{FOCUS ON MSC-DERIVED EXOSOMES AND THEIR ROLE IN NEUROPLASTICITY}

MSCs have multipotent mesodermal differentiation potential, but more importantly, they have demonstrated the ability 
to promote tissue repair through the release of paracrine factors, mainly a variety of growth factors, immunomodulatory cytokines and other trophic mediators, which make them an attractive therapeutic strategy for applications in inflammatory and chronic-degenerative diseases (Donders et al., 2018). In general, administration of MSCs or conditioned media from MSCs induce structural and functional benefits that reduce apoptosis at the lesion site, module proinflammatory response, provide a permissive environment for axonal extension, enhance neurogenesis and ameliorate neurological deficits (Cantinieaux et al., 2013; Qu and Zhang, 2017; Harris et al., 2018).

The composition of exosomal cargo determines the therapeutic potential of exosomes, and the fact that these vesicles were produced by cells with a therapeutic activity already described (like MSCs), increases this potential. Besides, MSCs are the most efficient exosome producing cells (Hall et al., 2016). Based on these facts and the paracrine hypothesis which establishes that the beneficial effect of stem cell therapy is due to stimulation of resident cell by secretion of bioactive molecules and release of EV, the use of exosomes could offer several advantages over MSCs such as a superior safety profile. Since these vesicles do not replicate they are exempted from uncontrolled division, unlike MSC, which during its isolation and expansion there is a risk of genetic damage which can lead to proliferation issues and spontaneous differentiation promoting tumor formation. Furthermore, exosomes lack metabolism, so the environment where they are administered will have no impact, also, they have a nanometric size, which decreases the possibility of microvascular thrombotic events, they can be sterilized by filtration, can be stored for long periods without presenting functional loss, and above all, have similar effects to those that MSCs exert with no side effects (Nakano et al., 2016; Ophelders et al., 2016; Gomzikova and Rizvanov, 2017; Xiong et al., 2017).

Many studies have shown that exosomes derived from MSCs can reduce cognitive problems associated with various neurological disorders models such as Traumatic Brain Injury (TBI; Xiong et al., 2017), Parkinson's disease and stroke (Yang Y. et al., 2017). It has been hypothesized that these vesicles act as paracrine activity effectors of MSCs by encapsulating and transferring many functional factors, including regulatory RNAs, proteins and lipids, however, exosome release is considered a cellular adaptation mechanism and its composition, biogenesis and secretion will depend on microenvironment with which cells interact (Xin et al., 2017a). An example of this cellular adaptation was reported by Harting et al. (2018) in a coculture of MSCs with ischemic tissue extracts, which demonstrated that MSCs can respond to an inflammatory stimulus by producing exosomes with a high anti-inflammatory capacity.

Recent studies show that proteins and regulatory RNAs within MSC-derived exosomes have synergistic effects in crucial processes such as metabolism, neuroinflammation, migration of cellular precursors and processes related to angiogenesis, neurogenesis and synaptogenesis, all activated after injuries (Nakano et al., 2016; Börger et al., 2017; Collino et al., 2017). In a study conducted by Li et al. (2017) in a TBI model, it was reported that dental pulp MSC-derived exosomes alter M1 microglia polarization and promote the transition to M2 phenotype. The M1/M2 transition inhibits the proinflammatory activity of M1 and increases M2 production of anti-inflammatory factors, which decreases neuroinflammation and promotes the functional recovery of rodents; however, the mechanisms that mediates these events remains unknown (Xin et al., 2013a; Doeppner et al., 2015; Li et al., 2017). Nakano et al. (2016) showed that neurological alterations caused by streptozotocin are restored by administration of MSC-derived exosomes, nevertheless, it was reported that there was no generation of new neurons, instead, these vesicles restore and protect the function of remaining neurons by increasing neuritic density and inhibiting oxidative stress damage, mainly lipid peroxidation of neuronal membranes.

In the last years, different studies demonstrated that MSC-derived exosomes promoted neurogenesis in different mice models of disease (Xin et al., 2013b; Doeppner et al., 2015; Zhang Y. et al., 2017). In these studies, treatment with exosomes increased the number of new-born neurons in neurogenic niches (the subventricular zone (SVZ) and dentate gyrus (DG)). However, the concrete cellular and molecular mechanism of this neurogenic process still unclear.

This demonstrates the multimodal therapeutic capabilities of the MSC-derived exosomes as MSC paracrine activity effectors, although the mechanisms remain unknown.

\section{MSC-Derived Exosomes miRNAs}

As mentioned above, exosomes can transfer different RNAs to adjacent cells. Among RNAs, miRNAs are the most widely studied (Cheng et al., 2018). miRNAs are a class of non-coding RNAs that functionally inhibit their respective messenger RNAs target by binding to the $3^{\prime}$ untranslated regions $\left(3^{\prime}\right.$ UTR) and are implicated in many biological processes such as embryonic development, proliferation, differentiation and apoptosis (Stevanato et al., 2016). It has been described that approximately $60 \%$ of genes are more than 1,000 miRNAs targets, and $70 \%$ of those miRNAs are expressed in the brain, where they regulate different neural and glial functions (Lei et al., 2015). Also, it was demonstrated that the proportion of miRNA is higher in exosomes than in their parent cells (Zhang et al., 2015). The number and type of miRNA within the exosomes is not a random process, instead, the cells selectively group the miRNAs, however, the process of packing RNAs into exosomes is poorly understood (Stevanato et al., 2016). Nevertheless, there are potential ways of sorting miRNAs into exosomes like the neural sphingomyelinase 2, the miRNA induced silencing complex and the miRNA motif sumoylation pathways, however, the underlying mechanisms remain unclear (Zhang et al., 2015).

Several in vitro and in vivo studies indicate that MSC exosomes transfer functional miRNAs to neural cells and promote neuritic remodeling and plasticity, as well as inhibit apoptosis, which subsequently promotes functional recovery (Xin et al., 2013b, 2017b; Cheng et al., 2018). Few studies have identified a single exosome cargo component that contributes to observed effects (Börger et al., 2017). For example, Xin et al. (2017b) demonstrated that exosomes enriched with miR-133b promote neurovascular plasticity and also reported that this 
miRNA increases secondary release of exosomes from astrocytes, which considerably enhances neuritic growth, however, they do not exclude the possibility that other cells are influenced by miR-133b. Baglio et al. (2015) analyzed MSC miRNA profiles of bone marrow and adipose tissue, among these miRNAs, there are some that are involved in MSC biology, such as miR-486 that regulates cellular senescence, or miR-143 with a key role in MSC immune response modulation, additionally, other miRNAs were identified, such as miR-191, miR-222, miR-21 and let-7a related to cell cycle progression, proliferation and angiogenesis modulation (Chen et al., 2010; Clark et al., 2014; Baglio et al., 2015).

On the other hand, it has been reported that exosomes also contain miR-98, miR-155 and miR-125a which have antiapoptotic activity (Ma et al., 2016; Cheng et al., 2018). Cheng et al. (2018), showed that in chronic inflammation and apoptotic conditions, miR-21 levels decrease considerably, however, MSCs in this condition secrete exosomes with high levels of miR21, which reduce apoptosis of cells that are in an environment of chronic inflammation. Furthermore, they demonstrated that miR-21 can bind to messenger RNA 3' UTR of PTEN, main inhibitor of the PI3K/Akt survival pathway in apoptosis mediated by $\mathrm{p} 53$ and phosphatidylinositol. Therefore miR-21 possibly promotes cell survival by inhibiting PTEN during apoptosis, triggering the activation of Akt and Bcl-2 and the decrease of Bad, Bax and caspase-3, eventually inhibiting apoptosis.

The miRNA-miR-17-92 cluster, formed by miR-17, miR18a, miR-19a, miR-19b, miR-20a and miR-92a, has shown to be implicated in neuritic remodeling and neurogenesis as established by Xin et al. (2017a). This cluster, like miR21, targets PTEN, allowing the activation of Akt and mTOR, which phosphorylate GSK-3 $\beta$, inhibiting its function. GSK-3 $\beta$ inactivation has been reported to stimulate axonal growth and central nervous system recovery (Eldar-Finkelman and Martinez, 2011; Xin et al., 2017a). Moreover, it has been described that MSC exosomes assist in neural differentiation by miR-124 delivering to neural precursor cells (NPCs). This miRNA suppresses Sox9 expression, implied in NPC multipotent capacity and maintenance, hence the effect of miR-124 on Sox 9 promotes NPC differentiation (Lee et al., 2014; Yang J. et al., 2017).

Understanding miRNA-regulated molecular mechanisms and their impact on the brain can likely be translated into therapies with positive clinical impact for $\mathrm{AD}$ and other neurodegenerative disorders in the future.

\section{MSC-Derived Exosomes Proteins}

Similar to miRNAs, proteins from exosomal cargo are important effectors of these vesicles. Currently, more than 900 proteins have been identified within MSC-derived exosomes (Kalra et al., 2012; Keerthikumar et al., 2016). Exosomal proteins can act as signaling molecules, receptors, cell adhesion molecules among other functions. For example, the expression of proteins such as nestin, neuro-D, growth-associated protein 43, synaptophysins, VEGF, FGF promote events such as neural development, synaptogenesis and angiogenesis (Chopp and Li, 2002). Katsuda et al. (2013) indicated that MSC exosomes from adipose tissue contain neprilysin, an enzyme capable of degrading $A \beta$, and in co-culture with cells designed for $A \beta$ exacerbated production, these exosomes significantly reduced levels of $A \beta 1-40$ and 1-42.

In different neurodegenerative disease models, it has been reported that MSCs interact with NPC in neurogenic niches of SVZ of lateral ventricles and the hippocampus DG through exosomes (Lee et al., 2013; Zhang and Chopp, 2015; Xin et al., 2017b; Yang Y. et al., 2017). However, the mechanisms by which exosomes interact with NPC and modify their behavior to promote neurogenesis, among other neuroplastic events, have not yet been determined. Nevertheless, some authors have associated some components with the activation (see Table 1), of the chemokine ligand (motif cc) 2 (CCL2), that functions as a neuronal activity modulator. MSCs release CCL2 to stimulate proliferation, migration and differentiation of NPC to neural and glial cells (Liu et al., 2007; Lee et al., 2013).

Another identified component is Sirtuin1 (SIRT1), which regulates transcription factors and cofactor deacetylation involved in angiogenesis, inflammation, response to oxidative stress and in neural development, associated with NPC proliferation and differentiation (Hu et al., 2014). SIRT1 forms a complex with Hairy/enhancer of Split 1 (Hes1), a transcriptional repressor of Mash1, responsible for the activation of neuronal specific transcription program. Under oxidizing conditions, this SIRT1/Hes1 complex deacetylates Mash1 promoter and recruits other co-repressors such as TLE1, which block neuronal differentiation, whereas under reducing conditions the SIRT1/Hes1 complex is not formed, therefore Hes 1 recruits transcriptional activators such as the CREB binding protein to the Mash1 promoter, resulting in a neural destiny of NPC (Libert et al., 2008).

McBride et al. (2017) found that MSC-derived exosomes transport Wnt3a proteins associated with the outer face of the exosomal membrane. This allows the activation of the Wnt/ $\beta$ catenin signaling pathway, the main canonical signaling process that regulates adult neurogenesis (Yin et al., 2007). It has been reported that this signaling increases in the hippocampus DG after the administration of MSC in TBI models and improves cognitive deficits, as a result of potentiation of neurogenesis. It has been described that this signaling increases in hippocampus DG after MSC administration in TBI models and improves cognitive deficits, associated with the potentiation of neurogenesis (Zhao et al., 2016a; McBride et al., 2017). Wnt3a and its active form $\beta$-catenin expression promote NPC expansion and differentiation into synaptically active neurons, whereas the absence of Wnt3a inhibits the differentiation of NPC to neurons (Yin et al., 2007).

Rodriguez-Grande et al. (2015) studied the effect of Pentraxin 3 (PTX3) protein on neurogenesis using a stroke model and reported that PTX3 is a key regulator of angiogenesis and neurogenesis, however, the molecular mechanisms involved have not been described yet. PTX3 is a protein with direct involvement in neuroinflammation in acute phases (Ummenthum et al., 2016). The inhibition of PTX3 reduces the number of capillaries in reperfusion areas after ischemia as well as the formation of new neurons (Rodriguez-Grande et al., 2015).

In the exosomal cargo, ephrins, are a pivotal regulator of the developmental process of axon guidance, cell migration, synapse 
TABLE 1 | Polypeptides identified in exosomes derivate from Mesenchymal Stem Cells (MSC).

\begin{tabular}{|c|c|c|c|c|}
\hline Protein name & Gene & UniProtKBa Acc. No. & $\mathrm{MW}^{\mathrm{b}}$ (kDa) & $\mathrm{pl}^{\mathrm{C}}$ \\
\hline 1. C-C motif chemokine 2 (CCL2) & CCL2 & P13500 & 11.02 & 9.40 \\
\hline 2. NAD-dependent protein deacetylase sirtuin-1 & SIRT1 & Q96EB6 & 81.68 & 4.55 \\
\hline 3. Protein Wnt-3a & WNT3A & P56704 & 39.36 & 8.52 \\
\hline 4. Pentraxin-related protein PTX3 & PTX3 & P26022 & 41.97 & 4.94 \\
\hline 5. Thrombospondin-1 & THBS1 & P07996 & 129.38 & 4.71 \\
\hline 6. Growth/differentiation factor 15 & GDF15 & Q99988 & 34.14 & 9.79 \\
\hline 7. Cell division control protein 42 & CDC42 & P60953 & 21.25 & 6.16 \\
\hline 8. Dihydropyrimidinase-related protein 2 & DPYSL2 & Q17555 & 62.29 & 5.95 \\
\hline 9. Prosaposin & PSAP & P07602 & 58.11 & 5.06 \\
\hline 10. Brain-derived neurotrophic factor & $B D N F$ & P23560 & 27.81 & 9.01 \\
\hline 11. Nerve growth factor & NGF & P01138 & 26.95 & 9.94 \\
\hline 12. Fibroblast growth factor 2 & FGF2 & P09038 & 30.77 & 11.18 \\
\hline 13. Stromal cell-derived factor 1 & CXCL12 & P48061 & 10.66 & 9.92 \\
\hline 14. Ephrin A-2 & EFNA2 & O43921 & 23.87 & 6.99 \\
\hline 15. Vascular endothelial growth factor & VEGFA & P15692 & 27.04 & 9.21 \\
\hline 16. Microtubule-associated protein tau & MAPT & P10636 & 78.92 & 6.25 \\
\hline 17. Beta-secretase 1 & BACE1 & P56817 & 55.76 & 5.31 \\
\hline 18. Amyloid-beta A4 protein & $A P P$ & P05067 & 86.94 & 4.73 \\
\hline 19. Prion protein & PRNP & P04156 & 27.66 & 9.13 \\
\hline 20. CD81 & $C D 81$ & P60033 & 25.80 & 5.09 \\
\hline 21. Tetraspanin-6 & TSPAN6 & O43657 & 27.56 & 8.44 \\
\hline 22. CD9 & CD9 & P21926 & 25.41 & 6.80 \\
\hline 23. Neutral sphingomyelinase 2 & SMPD3 & Q9NY59 & 71.03 & 5.52 \\
\hline
\end{tabular}

a UniProtKB Acc. Numb., UniProt Knowledgebase Accession Number. ${ }^{b} \mathrm{MW}$, Molecular weight. ${ }^{\mathrm{C}}$ pl, Isoelectric point.

formation and vascular formation but it is unknown the role they play in the adult organism (Wilkinson, 2001), to this account Holmberg et al. (2005) studied the role of A-class ephrins in the neural stem cell niche, and reported that ephrin-A2 (EFNA2) negatively regulates neural progenitor proliferation. Lack of expression EFNA2 and its receptor Eph7A result in active and ongoing neurogenesis, suggesting that neural cell replacement therapies may be achieved by modification of ephrin signaling pathways.

Dihydropyrimidinase-like 2 (DPYSL2) best known as collapsing response mediator protein 2 also is found in the exosomal cargo. DPYSL2 is a member of a family named for their roles in axonal growth cone collapse. Its main function is stabilizing microtubules, promoting neuritic outgrowth and modulating signaling processes (Pham et al., 2016). In the process of NPC senescence, the expression of DPYSL2 decreases with the age, consistent with the involvement in the neurodegeneration processes (Wang et al., 2016).

Prosaposin (PSAP) is another protein found in exosomes ( $\mathrm{Li}$ et al., 2010). PSAP is suggested to be an essential neurotrophic factor since its secretion stimulates proliferation and maturation of immature neurons in the hippocampus DG, as well as provides protection against apoptosis. It was reported that deficiency of PSAP precedes massive neuronal loss in neurotoxic environments (Morishita et al., 2014; Nabeka et al., 2017).

It has been recently demonstrated that THBS1 is present in the secretome of MSC and exosomes (Maumus et al., 2017). Blake et al. (2008) show that thrombospondin-1 (THBS1) is a physiological ligand for ApoER2 like Reelin. This study demonstrated that the first alternative physiological ligand for ApoER2 and VLDLR is capable of inducing Dab1 phosphorylation, but no other key events of the Reelin signaling pathway. Blake et al. (2008) also showed that
THBS1 increases the length of neuronal precursor chains and stabilizes the structure of established chains along the rostral migratory stream. These functions of THBS1 in neuronal migration could help replace neural cells in injured zones and ameliorate neurological deficits through the administration of exosomes.

An analysis of a bioinformatic database was performed in order to identify and classify exosomal cargo of MSC according to their biologic function and their interaction in the secretome. The 23 proteins described in Table 1 were classified by Protein Analysis Through Evolutionary Relationships (PANTHER) system (Mi et al., 2017) and were grouped according to their involvement in the different cellular biological processes. In this first approach, we found 12 different biological processes (Figure 1; a protein can participate in more than one cellular process). From these 12 biological processes, four main groups are mentioned as; (a) cellular processes with 17 members; (b) response to a stimulus with 12 members; (c) biological regulation with 11 members; and (d) development processes with nine members.

In the cellular processes group, there are 13 proteins involved in cellular communication and four proteins with a role in the movement of cellular components. The main proteins implicated in cellular communication are members of CXC chemokine family such as CCL2 (UniProt code P13500) and CXCL2 (UniProt code P19875; The UniProt Consortium, 2018). A recent work in murine models of neurodegeneration has associated these two proteins in cellular migration processes and enhanced proliferation and differentiation of neural precursors (Hong et al., 2015; Wang F. et al., 2017). In addition, another member of this family, CXCR4 expressed by neurons (UniProt code P61073) has been linked to inflammatory processes by activating microglia expressing CCR2 (UniProt 


\section{QPM polypeptides}

\section{GO Biological process (23 genes; 21 process hits)}

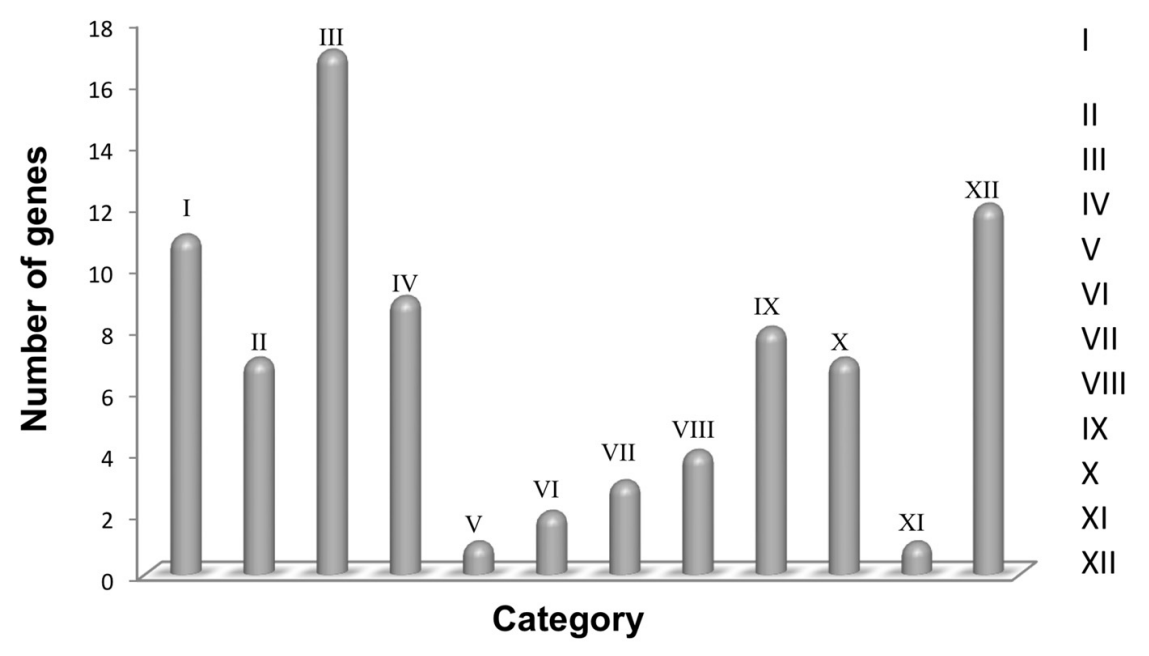

FIGURE 1 | Functional classification with PANTHER of the polypeptides found in exosomes. The UniProtKB IDs of proteins were submitted to the PANTHER database for their classification in Gene Ontology (GO) according to Biological. $X$-axis, categories of proteins. $Y$-axis, number of genes contained in each category.

code P41597; Liu C. et al., 2014). One study showed that knockout of CCR2 in an AD transgenic mouse model decreases microglia activation and increases $A \beta$ accumulation (Kiyota et al., 2013). This demonstrates the role of microglia in $\mathrm{A} \beta$ clearance and how its deficiency could speed up $\mathrm{AD}$ progression.

The second most important biological process was response to stimuli, mainly the regulation of protein phosphorylation, where the neurotrophic factors VEGF (UniProt code P15692), NGF (UniProt code P01138) and BDNF (UniProt code P23560) that modulate cell death cascades, increase production of proteins responsible for proliferation and maintenance of neurons. These factors also have roles in the outgrowth of dendrites and stabilizing synapses between neurons. In recent years, these neurotrophins have been considered as key regulators of adult neurogenesis and the changes in expression have been related to occurrence and development of cognitive impairments, even though the molecular mechanism is not completely elucidated (Ke and Zhang, 2013; Budni et al., 2015; Vilar and Mira, 2016). However, more data and support are needed to elucidate the mechanisms of neurotrophin imbalance and dysregulation in $\mathrm{AD}$ as well as possible therapeutic applications.

On the other hand, the main molecular functions identified for these molecules are related to catalytic activity, signal transduction and protein binding. In these cases, protein binding activity is the most representative molecular function for 12 proteins implied. In this group neurotrophins can also be found, due to their activity, which is mediated mainly by receptor phosphorylation which subsequently promotes the expression of proteins involved in the proliferation of the NPC, maintenance of the cell and ensuring neuronal survival (Bolijn and Lucassen, 2015).

This classification allowed us to generate a network of known and predicted protein-protein interaction using the STRING program (Szklarczyk et al., 2017). The interactome network represented in Figure $\mathbf{2}$ describes the interactome with a minimum required interaction score of 0.70 (high confidence) and highlights the biological processes in the regulation of axon extension (shown in red) with seven members in it and a false discovery rate (FDR) of $4.78 \mathrm{e}^{-09}$.

The second most important process for our analysis is axonogenesis with 10 members and an FDR of $8.91 \mathrm{e}^{-08}$, shown in blue. Interesting members related to axonogenesis are tau (MAPT UniProt code P10636) and cell division control protein 42 (CDC42 UniProt code P60953). It is known that tau is accumulated in the growth cone and its presence persists during the axonal elongation, however, understand the role of tau in axonogenesis is complicated because tau exists in different phosphorylation states and these states influence the subsequent localization of tau within neurons without implication of its role in the progression of AD (Zmuda and Rivas, 2000). CDC42 has roles in axon guidance and neurite formation particularly on growth cone through Robo signaling activation and actin filaments regulation (Matsuura et al., 2004). The CXCL12 and the neurotrophins BDNF and NGF are also associated with axonogenesis. Almost all proteins exert their function by acting as ligands (shown in green with an FDR $4.02 \mathrm{e}^{-08}$ ).

The proteins of interactome network are usually found in the extracellular space (shown in pink with an FDR $1.8 \mathrm{e}^{-06}$ ) where they can modulate the processes like the responses to stimuli previously described. The main pathway of this interactome 


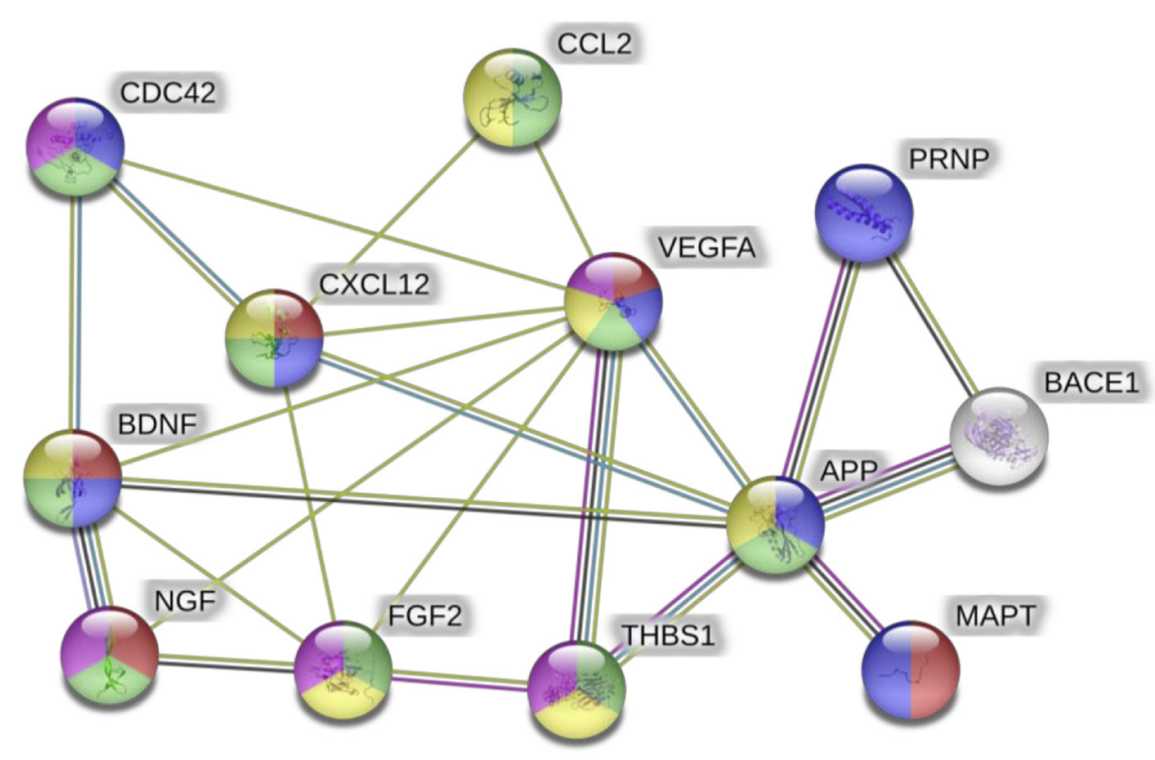

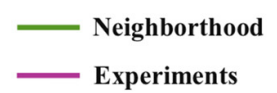

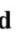

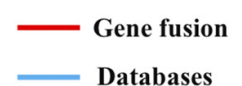

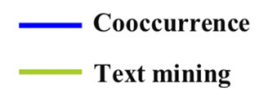

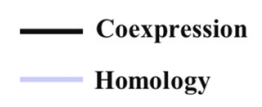

$\begin{array}{lll}\text { 1. Regulation of axon extension (7) } \\ \text { 2. Regulation of developmental growth (9) } \\ \text { 3. Axonogenesis } & (10) \\ \text { 4. Receptor binding } & (13) \\ \text { 5. Axon development } & (10)\end{array}$

6. Movement of cell or subcellular component (13)

7. Protein binding (8)

8. Extracellular space (12)

9. Rap1 signaling pathway (6)

FIGURE 2 | Interactome of polypeptides found in common exosomes related with a beta and tau protein. UniProtKB accession numbers were submitted to the String program to identify the predicted functional network. Lines in color represent different pieces of evidence for each identified interaction: red line, fusion; green line, neighborhood; blue line, cooccurrence; purple line, experimental; yellow line, text mining; light blue line, database; black line, coexpression.

network was the Rap1 signaling pathway (FDR 2.3e $\mathrm{e}^{-05}$ ) which has been reported to regulate vesicle secretion, cytoskeletal dynamics, proliferation and cell adhesion, (Shibasaki et al., 2007; van Hooren et al., 2012; Zhang Y.-L. et al., 2017). Possibly this way of signaling supports the delivery of the exosomal cargo.

On the other hand, it is interesting that VEGF participates in all analyzed processes. It has been reported that this neurotrophic factor evokes elements of brain plasticity like neurogenesis and neural progenitor cells migration (Chen et al., 2005). According to the interaction diagram, VEGF has synergistic effects with some neurotrophins and with components that mediate axonal guidance such as CDC42 and THBS1 (UniProt code P07996). This leads us to think that possibly the synergy of the exosomal cargo promotes better therapeutic responses compared to those that a single isolated component could. It would be important to study the effects of the composition of the exosomal charge on the progression of $\mathrm{AD}$ in both interactions with $\mathrm{A} \beta$ and the tau protein, as well as the effects it could have on neuroplastic events, mainly neurogenesis and synaptogenesis.

\section{CONCLUSION AND PERSPECTIVES}

Despite the great advances in $\mathrm{AD}$ research, the molecular mechanisms underlying this devastating disease have not been fully unveiled. However, remarkable neuropathological studies have provided the largest contribution to the knowledge of the mechanisms involved in the pathological amyloidogenic processing of $\mathrm{A} \beta$ as well as hyperphosphorylated tau aggregation into paired helical filaments. Unfortunately, there remains a need to find an accurate diagnosis, in addition to generating really effective treatments; thus, it is necessary to use novel approaches to understand the molecular and cellular mechanisms of $\mathrm{AD}$ in order to identify new 
therapeutic strategies that allow to delay, reverse or, in the best case, to avoid the normal pathological processing of this disease.

The use of proteomic study technologies plus the advent of induced pluripotent stem cells and three-dimensional culture technologies, has made it possible to generate novel in vitro 3D neural cell culture models that replicate $\mathrm{AD}$ pathologies, allowing us to explore new perspectives on the origin of the disease and its progression, for example the influence of some proteins in the misfolding of $\mathrm{A} \beta$ and the tau protein and its resistance to degradation. These in vitro $3 \mathrm{D}$ neural cell culture models also could explore the biochemical composition and modulation of exosomes and their role in disease progression. These advances have revolutionized the potential to generate novel platforms that can be used to study the mechanisms of pathology or to develop novel diagnostic and therapeutic tools in a brain-like environment.

Currently, MSC therapy has emerged as a promising strategy for treating different neurodegenerative disorders via tissue repair, however, the risks of tumor formation, cellular rejection and thrombosis in MSCs transplantation remain unresolved. Currently, the cell-free therapy using MSC-derived exosomes might constitute an alternative because of their advantages over MSCs. There are different studies indicating that exosomes act as an important mediator of the information exchange between MSCs and NPC. The exchange of miRNA and proteins between cell to cell through exosomes can reduce the neuroinflammation, promote neurogenesis and angiogenesis rescue learning impairments and improve functional recovery. However, the concrete mechanisms involved in the positive effects induced by MSCs-derived exosomes in $\mathrm{AD}$ are still unclear. Given a variety of functions and multiple molecules in exosomal cargo, is necessary that other studies analyze all

\section{REFERENCES}

Abels, E. R., and Breakefield, X. O. (2016). Introduction to extracellular vesicles: biogenesis, RNA cargo selection, content, release, and uptake. Cell. Mol. Neurobiol. 36, 301-312. doi: 10.1007/s10571-016-0366-Z

Angeloni, N. L., McMahon, K. M., Swaminathan, S., Plebanek, M. P., Osman, I., Volpert, O. V., et al. (2016). Pathways for modulating exosome lipids identified by high-density lipoprotein-like nanoparticle binding to scavenger receptor type B-1. Sci. Rep. 6:22915. doi: 10.1038/srep22915

Baglio, S. R., Rooijers, K., Koppers-Lalic, D., Verweij, F. J., Pérez Lanzón, M., Zini, N., et al. (2015). Human bone marrow- and adipose-mesenchymal stem cells secrete exosomes enriched in distinctive miRNA and tRNA species. Stem Cell Res. Ther. 6:127. doi: 10.1186/s13287-015-0116-Z

Bang, C., and Thum, T. (2012). Exosomes: new players in cell-cell communication. Int. J. Biochem. Cell Biol. 44, 2060-2064. doi: 10.1016/j.biocel.2012. 08.007

Baumann, K., Mandelkow, E.-M., Biernat, J., Piwnica-Worms, H., and Mandelkow, E. (1993). Abnormal Alzheimer-like phosphorylation of tau-protein by cyclin-dependent kinases $\mathrm{cdk} 2$ and $\mathrm{cdk} 5$. FEBS Lett. 336, 417-424. doi: 10.1016/0014-5793(93)80849-p

Beer, K. B., and Wehman, A. M. (2017). Mechanisms and functions of extracellular vesicle release in vivo-What we can learn from flies and worms. Cell Adh. Migr. 11, 135-150. doi: 10.1080/19336918.2016.1236899

Blake, S. M., Strasser, V., Andrade, N., Duit, S., Hofbauer, R., Schneider, W. J., et al. (2008). Thrombospondin-1 binds to ApoER2 and VLDL receptor and functions in postnatal neuronal migration. EMBO J. 27, 3069-3080. doi: 10.1038/emboj.2008.223 interaction and understand the relation between the intrinsic potential that is glimpsed in the combination of the use of exosome therapy and the participation of their cargo (miRNA and/or proteins) combined with the proteomic and bioinformatic analysis of those pathways that participate in this therapeutic modulation.

The bioinformatic analysis performed, allowed us to focus on possible candidates with an important role in neurogenesis and neuroplasticity or even identify some potential pathways implicated in AD's patient's progress. This would allow us to use exosomes with different therapeutic approaches, for example, the modification of exosomes with some classes of proteins or miRNAs, with effects on tissue repair, maintenance of cellular homeostasis or impairing the disease progression.

\section{AUTHOR CONTRIBUTIONS}

ER-Z, MH-S, BM, YG-M, AM-A and AC-A: equal contribution for the literature search, writing and correcting of this review article.

\section{FUNDING}

The present work was sponsored by CONACYT scholarship \#487713 and by FondoMixto de Ciencia y Tecnología del Estado de Jalisco grant JAL-2014-0-250508.

\section{ACKNOWLEDGMENTS}

We also would like to thank Ean Hundley and Estefanía Vázquez from CIATEJ/Peace Corps and University of Guadalajara, respectively for their valuable efforts in editing the English language of the manuscript.

Bolijn, S., and Lucassen, P. J. (2015). How the body talks to the brain; peripheral mediators of physical activity-induced proliferation in the adult hippocampus. Brain Plasticity 1, 5-27. doi: 10.3233/bpl-150020

Börger, V., Bremer, M., Ferrer-Tur, R., Gockeln, L., Stambouli, O., Becic, A., et al. (2017). Mesenchymal stem/stromal cell-derived extracellular vesicles and their potential as novel immunomodulatory therapeutic agents. Int. J. Mol. Sci. 18:E1450. doi: 10.3390/ijms18071450

Braak, H., and Braak, E. (1996). Evolution of the neuropathology of Alzheimer's disease. Acta Neurol. Scand. Suppl. 165, 3-12. doi: 10.1111/j.1600-0404.1996. tb05866.x

Budni, J., Bellettini-Santos, T., Mina, F., Garcez, M. L., and Zugno, A. I. (2015). The involvement of BDNF, NGF and GDNF in aging and Alzheimer's disease. Aging Dis. 6, 331-341. doi: 10.14336/ad.2015.0825

Camacho, L., Guerrero, P., and Marchetti, D. (2013). MicroRNA and protein profiling of brain metastasis competent cell-derived exosomes. PLoS One 8:e73790. doi: 10.1371/journal.pone.0073790

Cantinieaux, D., Quertainmont, R., Blacher, S., Rossi, L., Wanet, T., Noël, A., et al. (2013). Conditioned medium from bone marrow-derived mesenchymal stem cells improves recovery after spinal cord injury in rats: an original strategy to avoid cell transplantation. PLoS One 8:e69515. doi: 10.1371/journal.pone. 0069515

Chen, T. S., Lai, R. C., Lee, M. M., Choo, A. B., Lee, C. N., and Lim, S. K. (2010). Mesenchymal stem cell secretes microparticles enriched in pre-microRNAs. Nucleic Acids Res. 38, 215-224. doi: 10.1093/nar/gkp857

Chen, J., Zhang, C., Jiang, H., Li, Y., Zhang, L., Robin, A., et al. (2005). Atorvastatin induction of VEGF and BDNF promotes brain plasticity after stroke in mice. J. Cereb. Blood Flow Metab. 25, 281-290. doi: 10.1038/sj.jcbfm.9600034 
Chen, J. J., Zhao, B., Zhao, J., and Li, S. (2017). Potential roles of exosomal micrornas as diagnostic biomarkers and therapeutic application in Alzheimer's disease. Neural Plast. 2017:7027380. doi: 10.1155/2017/7027380

Cheng, L., Wu, S., Zhang, K., Qing, Y., and Xu, T. (2017). A comprehensive overview of exosomes in ovarian cancer: emerging biomarkers and therapeutic strategies. J. Ovarian Res. 10:73. doi: 10.1186/s13048-017-0368-6

Cheng, X., Zhang, G., Zhang, L., Hu, Y., Zhang, K., Sun, X., et al. (2018). Mesenchymal stem cells deliver exogenous miR-21 via exosomes to inhibit nucleus pulposus cell apoptosis and reduce intervertebral disc degeneration. J. Cell. Mol. Med. 22, 261-276. doi: 10.1111/jcmm.13316

Chiarini, A., Armato, U., Gardenal, E., Gui, L., and Dal Prà, I. (2017). Amyloid $\beta$-exposed human astrocytes overproduce phospho-tau and overrelease it within exosomes, effects suppressed by calcilytic NPS 2143-further implications for Alzheimer's therapy. Front. Neurosci. 11:217. doi: 10.3389/fnins.2017. 00217

Cho, H., Choi, J. Y., Hwang, M. S., Kim, Y. J., Lee, H. M., Lee, H. S., et al. (2016). In vivo cortical spreading pattern of tau and amyloid in the Alzheimer disease spectrum. Ann. Neurol. 80, 247-258. doi: 10.1002/ana.24711

Chopp, M., and Li, Y. (2002). Treatment of neural injury with marrow stromal cells. Lancet Neurol. 1, 92-100. doi: 10.1016/s1474-4422(02)00040-6

Clark, E. A., Kalomoiris, S., Nolta, J. A., and Fierro, F. A. (2014). Concise review: MicroRNA function in multipotent mesenchymal stromal cells. Stem Cells 32, 1074-1082. doi: 10.1002/stem.1623

Collino, F., Pomatto, M., Bruno, S., Lindoso, R. S., Tapparo, M., Sicheng, W., et al. (2017). Exosome and microvesicle-enriched fractions isolated from mesenchymal stem cells by gradient separation showed different molecular signatures and functions on renal tubular epithelial cells. Stem Cell Rev. 13, 226-243. doi: 10.1007/s12015-016-9713-1

Colombo, M., Raposo, G., and Théry, C. (2014). Biogenesis, secretion, and intercellular interactions of exosomes and other extracellular vesicles. Annu. Rev. Cell Dev. Biol. 30, 255-289. doi: 10.1146/annurev-cellbio-101512122326

Correas, I., Díaz-Nido, J., and Avila, J. (1992). Microtubule-associated protein tau is phosphorylated by protein kinase $\mathrm{C}$ on its tubulin binding domain. J. Biol. Chem. 267, 15721-15728.

de Jong, O. G., Verhaar, M. C., Chen, Y., Vader, P., Gremmels, H., Posthuma, G., et al. (2012). Cellular stress conditions are reflected in the protein and RNA content of endothelial cell-derived exosomes. J. Extracell. Vesicles 1:18396. doi: 10.3402/jev.v1i0.18396

Dinkins, M. B., Enasko, J., Hernandez, C., Wang, G., Kong, J., Helwa, I., et al. (2016). Neutral sphingomyelinase-2 deficiency ameliorates Alzheimer's disease pathology and improves cognition in the 5XFAD mouse. J. Neurosci. 36, 8653-8667. doi: 10.1523/JNEUROSCI.1429-16.2016

Doeppner, T. R., Herz, J., Görgens, A., Schlechter, J., Ludwig, A. K., Radtke, S., et al. (2015). Extracellular vesicles improve post-stroke neuroregeneration and prevent postischemic immunosuppression. Stem Cells Transl. Med. 4, 1131-1143. doi: 10.5966/sctm.2015-0078

Donders, R., Bogie, J. F. J., Ravanidis, S., Gervois, P., Vanheusden, M., Marée, R., et al. (2018). Human wharton's jelly-derived stem cells display a distinct immunomodulatory and proregenerative transcriptional signature compared to bone marrow-derived stem cells. Stem Cells Dev. 27, 65-84. doi: 10.1089/scd. 2017.0029

Drommelschmidt, K., Serdar, M., Bendix, I., Herz, J., Bertling, F., Prager, S., et al. (2017). Mesenchymal stem cell-derived extracellular vesicles ameliorate inflammation-induced preterm brain injury. Brain Behav. Immun. 60, 220-232. doi: 10.1016/j.bbi.2016.11.011

Eitan, E., Suire, C., Zhang, S., and Mattson, M. P. (2016). Impact of lysosome status on extracellular vesicle content and release. Ageing Res. Rev. 32, 65-74. doi: 10.1016/j.arr.2016.05.001

Eldar-Finkelman, H., and Martinez, A. (2011). GSK-3 inhibitors: preclinical and clinical focus on CNS. Front. Mol. Neurosci. 4:32. doi: 10.3389/fnmol.2011. 00032

Emmanouilidou, E., Melachroinou, K., Roumeliotis, T., Garbis, S. D., Ntzouni, M., Margaritis, L. H., et al. (2010). Cell-produced $\alpha$-synuclein is secreted in a calcium-dependent manner by exosomes and impacts neuronal survival. J. Neurosci. 30, 6838-6851. doi: 10.1523/JNEUROSCI.5699-09.2010

Escola, J. M., Kleijmeer, M. J., Stoorvogel, W., Griffith, J. M., Yoshie, O., and Geuze, H. J. (1998). Selective enrichment of tetraspan proteins on the internal vesicles of multivesicular endosomes and on exosomes secreted by human B-lymphocytes. J. Biol. Chem. 273, 20121-20127. doi: 10.1074/jbc.273.32. 20121

Falker, C., Hartmann, A., Guett, I., Dohler, F., Altmeppen, H., Betzel, C., et al. (2016). Exosomal cellular prion protein drives fibrillization of amyloid $\beta$ and counteracts amyloid $\beta$-mediated neurotoxicity. J. Neurochem. 137, 88-100. doi: $10.1111 /$ jnc. 13514

Gauthier, S. A., Pérez-González, R., Sharma, A., Huang, F. K., Alldred, M. J., Pawlik, M., et al. (2017). Enhanced exosome secretion in Down syndrome brain-a protective mechanism to alleviate neuronal endosomal abnormalities. Acta Neuropathol. Commun. 5:65. doi: 10.1186/s40478-017-0466-0

Ghosh, A., and Giese, K. P. (2015). Calcium/calmodulin-dependent kinase II and Alzheimer's disease. Mol. Brain 8:78. doi: 10.1186/s13041-015-0166-2

Goetzl, E. J., Mustapic, M., Kapogiannis, D., Eitan, E., Lobach, I. V., Goetzl, L., et al. (2016). Cargo proteins of plasma astrocyte-derived exosomes in Alzheimer's disease. FASEB J. 30, 3853-3859. doi: 10.1096/fj.201600756r

Gomzikova, M. O., and Rizvanov, A. A. (2017). Current trends in regenerative medicine: from cell to cell-free therapy. BioNanoScience 7, 240-245. doi: 10.1007/s12668-016-0348-0

Greenberg, S. M., Koo, E. H., Selkoe, D. J., Qiu, W. Q., and Kosik, K. S. (1994). Secreted $\beta$-amyloid precursor protein stimulates mitogen-activated protein kinase and enhances tau phosphorylation. Proc. Natl. Acad. Sci. U S A 91, 7104-7108. doi: 10.1073/pnas.91.15.7104

Grundke-Iqbal, I., Iqbal, K., Tung, Y. C., Quinlan, M., Wisniewski, H. M., and Binder, L. I. (1986). Abnormal phosphorylation of the microtubule-associated protein tau (tau) in Alzheimer cytoskeletal pathology. Proc. Natl. Acad. Sci. U S A 83, 4913-4917. doi: 10.1073/pnas.83.13.4913

Guduric-Fuchs, J., O'Connor, A., Camp, B., O’Neill, C. L., Medina, R. J., and Simpson, D. A. (2012). Selective extracellular vesicle-mediated export of an overlapping set of microRNAs from multiple cell types. BMC Genomics 13:357. doi: 10.1186/1471-2164-13-357

Guix, F. X., Sannerud, R., Berditchevski, F., Arranz, A. M., Horré, K., Snellinx, A., et al. (2017). Tetraspanin 6: a pivotal protein of the multiple vesicular body determining exosome release and lysosomal degradation of amyloid precursor protein fragments. Mol. Neurodegener. 12:25. doi: 10.1186/s13024-0170165-0

Hall, J., Prabhakar, S., Balaj, L., Lai, C. P., Cerione, R. A., and Breakefield, X. O. (2016). Delivery of therapeutic proteins via extracellular vesicles: review and potential treatments for Parkinson's disease, glioma, and schwannoma. Cell. Mol. Neurobiol. 36, 417-427. doi: 10.1007/s10571-015-0309-0

Harris, V. K., Stark, J., Vyshkina, T., Blackshear, L., Joo, G., Stefanova, V., et al. (2018). Phase I trial of intrathecal mesenchymal stem cell-derived neural progenitors in progressive multiple sclerosis. EBioMedicine 29, 23-30. doi: 10.1016/j.ebiom.2018.02.002

Harting, M. T., Srivastava, A. K., Zhaorigetu, S., Bair, H., Prabhakara, K. S., Toledano Furman, N. E., et al. (2018). Inflammation-stimulated mesenchymal stromal cell-derived extracellular vesicles attenuate inflammation. Stem Cells 36, 79-90. doi: 10.1002/stem.2730

Henne, W. M., Stenmark, H., and Emr, S. D. (2013). Molecular mechanisms of the membrane sculpting ESCRT pathway. Cold Spring Harb. Perspect. Biol. 5:a016766. doi: 10.1101/cshperspect.a016766

Holmberg, J., Armulik, A., Senti, K.-A., Edoff, K., Spalding, K., Momma, S., et al. (2005). Ephrin-A2 reverse signaling negatively regulates neural progenitor proliferation and neurogenesis. Genes Dev. 19, 462-471. doi: 10.1101/gad. 326905

Hong, Y. R., Lee, H., Park, M. H., Lee, J. K., Lee, J. Y., Suh, H. D., et al. (2015). CCL2 induces neural stem cell proliferation and neuronal differentiation in Niemann-Pick type C mice. J. Vet. Med. Sci. 77, 693-699. doi: 10.1292/jvms. 14-0352

Hu, B., Guo, Y., Chen, C., Li, Q., Niu, X., Guo, S., et al. (2014). Repression of SIRT1 promotes the differentiation of mouse induced pluripotent stem cells into neural stem cells. Cell. Mol. Neurobiol. 34, 905-912. doi: 10.1007/s10571014-0071-8

Hurley, J. H., and Hanson, P. I. (2010). Membrane budding and scission by the ESCRT machinery: it's all in the neck. Nat. Rev. Mol. Cell Biol. 11, 556-566. doi: $10.1038 / \mathrm{nrm} 2937$

Ikezu, T., Ikezu, S., Varnum, M., Wolozin, B., Butovsky, O., Kügler, S., et al. (2016). Microglial exosomes propagate tau protein from the entorhinal cortex to the 
hippocampus: an early pathophysiology of Alzheimer's disease. Alzheimers Dement. 12, P339-P340. doi: 10.1016/j.jalz.2016.06.624

Jaber, N., Mohd-Naim, N., Wang, Z., DeLeon, J. L., Kim, S., Zhong, H., et al. (2016). Vps34 regulates Rab7 and late endocytic trafficking through recruitment of the GTPase-activating protein Armus. J. Cell Sci. 129, 4424-4435. doi: 10.1242/jcs. 192260

Jaber, V., Zhao, Y., and Lukiw, W. J. (2017). Alterations in micro RNA-messenger RNA (miRNA-mRNA) coupled signaling networks in sporadic Alzheimer's disease (AD) hippocampal CA1. J. Alzheimers Dis. Parkinsonism 7:312. doi: 10.4172/2161-0460.1000312

Joshi, P., Benussi, L., Furlan, R., Ghidoni, R., and Verderio, C. (2015). Extracellular vesicles in Alzheimer's disease: friends or foes? Focus on $A \beta$-vesicle interaction. Int. J. Mol. Sci. 16, 4800-4813. doi: 10.3390/ijms16034800

Kalra, H., Simpson, R. J., Ji, H., Aikawa, E., Altevogt, P., Askenase, P., et al. (2012). Vesiclepedia: a compendium for extracellular vesicles with continuous community annotation. PLoS Biol. 10:e1001450. doi: 10.1371/journal.pbio. 1001450

Katsuda, T., Tsuchiya, R., Kosaka, N., Yoshioka, Y., Takagaki, K., Oki, K., et al. (2013). Human adipose tissue-derived mesenchymal stem cells secrete functional neprilysin-bound exosomes. Sci. Rep. 3:1197. doi: 10.1038/srep 01197

Ke, X.-J., and Zhang, J.-J. (2013). Changes in HIF-1 $\alpha$, VEGF, NGF and BDNF levels in cerebrospinal fluid and their relationship with cognitive impairment in patients with cerebral infarction. J. Huazhong Univ. Sci. Technolog. Med. Sci. 33, 433-437. doi: 10.1007/s11596-013-1137-4

Keerthikumar, S., Chisanga, D., Ariyaratne, D., Al Saffar, H., Anand, S., Zhao, K., et al. (2016). ExoCarta: a web-based compendium of exosomal cargo. J. Mol. Biol. 428, 688-692. doi: 10.1016/j.jmb.2015.09.019

Kessels, H. W., Nguyen, L. N., Nabavi, S., and Malinow, R. (2010). The prion protein as a receptor for amyloid- $\beta$. Nature 466, E3-E4; discussion E4-E5. doi: 10.1038/nature09217

Kim, H. J., Lee, J. H., and Kim, S. H. (2010). Therapeutic effects of human mesenchymal stem cells on traumatic brain injury in rats: secretion of neurotrophic factors and inhibition of apoptosis. J. Neurotrauma 27, 131-138. doi: 10.1089/neu.2008.0818

Kiyota, T., Gendelman, H. E., Weir, R. A., Higgins, E. E., Zhang, G., and Jain, M. (2013). CCL2 affects $\beta$-amyloidosis and progressive neurocognitive dysfunction in a mouse model of Alzheimer's disease. Neurobiol. Aging 34, 1060-1068. doi: 10.1016/j.neurobiolaging.2012.08.009

Kizuka, Y., Kitazume, S., Fujinawa, R., Saito, T., Iwata, N., Saido, T. C., et al. (2015). An aberrant sugar modification of BACE1 blocks its lysosomal targeting in Alzheimer's disease. EMBO Mol. Med. 7, 175-189. doi: 10.15252/emmm. 201404438

Koelsch, G. (2017). BACE1 function and inhibition: implications of intervention in the amyloid pathway of Alzheimer's disease pathology. Molecules 22:E1723. doi: $10.3390 /$ molecules 22101723

Kosaka, N., Iguchi, H., Yoshioka, Y., Takeshita, F., Matsuki, Y., and Ochiya, T. (2010). Secretory mechanisms and intercellular transfer of microRNAs in living cells. J. Biol. Chem. 285, 17442-17452. doi: 10.1074/jbc.M110.107821

Kosik, K. S., Joachim, C. L., and Selkoe, D. J. (1986). Microtubule-associated protein tau (tau) is a major antigenic component of paired helical filaments in Alzheimer disease. Proc. Natl. Acad. Sci. U S A 83, 4044-4048. doi: 10.1073/pnas.83.11.4044

Kurozumi, K., Nakamura, K., Tamiya, T., Kawano, Y., Kobune, M., Hirai, S., et al. (2004). BDNF gene-modified mesenchymal stem cells promote functional recovery and reduce infarct size in the rat middle cerebral artery occlusion model. Mol. Ther. 9, 189-197. doi: 10.1016/j.ymthe.2003.10.012

Lai, R. C., Arslan, F., Lee, M. M., Sze, N. S., Choo, A., Chen, T. S., et al. (2010). Exosome secreted by MSC reduces myocardial ischemia/reperfusion injury. Stem Cell Res. 4, 214-222. doi: 10.1016/j.scr.2009.12.003

Laulagnier, K., Javalet, C., Hemming, F. J., Chivet, M., Lachenal, G., Blot, B., et al. (2018). Amyloid precursor protein products concentrate in a subset of exosomes specifically endocytosed by neurons. Cell. Mol. Life Sci. 75, 757-773. doi: 10.1007/s00018-017-2664-0

Lauren, J., Gimbel, D. A., Nygaard, H. B., Gilbert, J. W., and Strittmatter, S. M. (2009). Cellular prion protein mediates impairment of synaptic plasticity by amyloid- $\beta$ oligomers. Nature 457, 1128-1132. doi: 10.1038/nature 07761
Lee, H. K., Finniss, S., Cazacu, S., Xiang, C., and Brodie, C. (2014). Mesenchymal stem cells deliver exogenous miRNAs to neural cells and induce their differentiation and glutamate transporter expression. Stem Cells Dev. 23, 2851-2861. doi: 10.1089/scd.2014.0146

Lee, H., Kang, J. E., Lee, J. K., Bae, J. S., and Jin, H. K. (2013). Bone-marrow-derived mesenchymal stem cells promote proliferation and neuronal differentiation of Niemann-Pick type $\mathrm{C}$ mouse neural stem cells by upregulation and secretion of CCL2. Hum. Gene Ther. 24, 655-669. doi: 10.1089/hum.2013.001

Lei, X., Lei, L., Zhang, Z., Zhang, Z., and Cheng, Y. (2015). Downregulated miR-29c correlates with increased BACE1 expression in sporadic Alzheimer's disease. Int. J. Clin. Exp. Pathol. 8, 1565-1574.

Levy, E. (2017). Exosomes in the diseased brain: first insights from in vivo studies. Front. Neurosci. 11:142. doi: 10.3389/fnins.2017.00142

Li, Y., Chen, J., Chen, X. G., Wang, L., Gautam, S. C., Xu, Y. X., et al. (2002). Human marrow stromal cell therapy for stroke in rat: neurotrophins and functional recovery. Neurology 59, 514-523. doi: 10.1212/wnl.59.4.514

Li, Y., and Kim, J. (2016). CB2 cannabinoid receptor knockout in mice impairs contextual long-term memory and enhances spatial working memory. Neural Plast. 2016:9817089. doi: 10.1155/2016/9817089

Li, N., Sarojini, H., An, J., and Wang, E. (2010). Prosaposin in the secretome of marrow stroma-derived neural progenitor cells protects neural cells from apoptotic death. J. Neurochem. 112, 1527-1538. doi: 10.1111/j.1471-4159.2009. 06565.x

Li, Y., Yang, Y. Y., Ren, J. L., Xu, F., Chen, F. M., and Li, A. (2017). Exosomes secreted by stem cells from human exfoliated deciduous teeth contribute to functional recovery after traumatic brain injury by shifting microglia M1/M2 polarization in rats. Stem Cell Res. Ther. 8:198. doi: 10.1186/s13287017-0648-5

Libert, S., Cohen, D., and Guarente, L. (2008). Neurogenesis directed by Sirt1. Nat. Cell Biol. 10, 373-374. doi: 10.1038/ncb0408-373

Liu, C., Cui, G., Zhu, M., Kang, X., and Guo, H. (2014). Neuroinflammation in Alzheimer's disease: chemokines produced by astrocytes and chemokine receptors. Int. J. Clin. Exp. Pathol. 7, 8342-8355.

Liu, C. G., Song, J., Zhang, Y. Q., and Wang, P. C. (2014). MicroRNA-193b is a regulator of amyloid precursor protein in the blood and cerebrospinal fluid derived exosomal microRNA-193b is a biomarker of Alzheimer's disease. Mol. Med. Rep. 10, 2395-2400. doi: 10.3892/mmr.2014.2484

Liu, X. S., Zhang, Z. G., Zhang, R. L., Gregg, S. R., Wang, L., Yier, T., et al. (2007). Chemokine ligand 2 (CCL2) induces migration and differentiation of subventricular zone cells after stroke. J. Neurosci. Res. 85, 2120-2125. doi: 10.1002/jnr.21359

Lugli, G., Cohen, A. M., Bennett, D. A., Shah, R. C., Fields, C. J., Hernandez, A. G., et al. (2015). Plasma exosomal miRNAs in persons with and without alzheimer disease: altered expression and prospects for biomarkers. PLoS One 10:e0139233. doi: 10.1371/journal.pone.0139233

Luna-Muñoz, J., Chávez-Macías, L., García-Sierra, F., and Mena, R. (2007). Earliest stages of tau conformational changes are related to the appearance of a sequence of specific phospho-dependent tau epitopes in Alzheimer's disease. J. Alzheimers Dis. 12, 365-375. doi: 10.3233/jad-2007-12410

Ma, J. F., Zang, L. N., Xi, Y. M., Yang, W. J., and Zou, D. (2016). MiR-125a Rs12976445 polymorphism is associated with the apoptosis status of nucleus pulposus cells and the risk of intervertebral disc degeneration. Cell. Physiol. Biochem. 38, 295-305. doi: 10.1159/000438630

Malm, T., Loppi, S., and Kanninen, K. M. (2016). Exosomes in Alzheimer's disease. Neurochem. Int. 97, 193-199. doi: 10.1016/j.neuint.2016.04.011

Mandelkow, E. M., Drewes, G., Biernat, J., Gustke, N., Van Lint, J., Vandenheede, J. R., et al. (1992). Glycogen synthase kinase-3 and the Alzheimer-like state of microtubule-associated protein tau. FEBS Lett. 314, 315-321. doi: 10.1016/0014-5793(92)81496-9

Matsuura, R., Tanaka, H., and Go, M. J. (2004). Distinct functions of Rac1 and Cdc42 during axon guidance and growth cone morphogenesis in Drosophila. Eur. J. Neurosci. 19, 21-31. doi: 10.1046/j.1460-9568.2003.03084.x

Matthay, M. A., Pati, S., and Lee, J. W. (2017). Concise review: mesenchymal stem (Stromal) cells: biology and preclinical evidence for therapeutic potential for organ dysfunction following trauma or sepsis. Stem Cells 35, 316-324. doi: 10.1002/stem.2551

Maumus, M., Manferdini, C., Toupet, K., Chuchana, P., Casteilla, L., Gachet, M., et al. (2017). Thrombospondin-1 partly mediates the cartilage protective effect 
of adipose-derived mesenchymal stem cells in osteoarthritis. Front Immunol. 8:1638. doi: 10.3389/fimmu.2017.01638

McBride, J. D., Rodriguez-Menocal, L., Guzman, W., Candanedo, A., GarciaContreras, M., and Badiavas, E. V. (2017). Bone marrow mesenchymal stem cell-derived $\mathrm{CD}^{+} 3^{+}$exosomes transport Wnt3a exteriorly and enhance dermal fibroblast proliferation, migration and angiogenesis in vitro. Stem Cells Dev. 26, 1384-1398. doi: 10.1089/scd.2017.0087

Mi, H., Huang, X., Muruganujan, A., Tang, H., Mills, C., Kang, D., et al. (2017). PANTHER version 11: expanded annotation data from Gene Ontology and Reactome pathways and data analysis tool enhancements. Nucleic Acids Res. 45, D183-D189. doi: 10.1093/nar/gkw1138

Miranda, A. M., Lasiecka, Z. M., Xu, Y., Neufeld, J., Shahriar, S., Simoes, S., et al. (2018). Neuronal lysosomal dysfunction releases exosomes harboring APP C-terminal fragments and unique lipid signatures. Nat. Commun. 9:291. doi: 10.1038/s41467-017-02533-w

Mitsialis, S. A., and Kourembanas, S. (2016). Stem cell-based therapies for the newborn lung and brain: possibilities and challenges. Semin. Perinatol. 40, 138-151. doi: 10.1053/j.semperi.2015.12.002

Mizushima, N., and Komatsu, M. (2011). Autophagy: renovation of cells and tissues. Cell 147, 728-741. doi: 10.1016/j.cell.2011.10.026

Morishita, M., Nabeka, H., Shimokawa, T., Miyawaki, K., Doihara, T., Saito, S., et al. (2014). Temporal changes in prosaposin expression in the rat dentate gyrus after birth. PLoS One 9:e95883. doi: 10.1371/journal.pone.00 95883

Mroczko, B., Groblewska, M., Litman-Zawadzka, A., Kornhuber, J., and Lewczuk, P. (2018). Amyloid $\beta$ oligomers (A $\beta O s)$ in Alzheimer's disease. J. Neural Transm. 125, 177-191. doi: 10.1007/s00702-017-1820-x

Mulcahy, L. A., Pink, R. C., and Carter, D. R. (2014). Routes and mechanisms of extracellular vesicle uptake. J. Extracell. Vesicles 3:24641. doi: 10.3402/jev.v3. 24641

Munro, K. M., Nash, A., Pigoni, M., Lichtenthaler, S. F., and Gunnersen, J. M. (2016). Functions of the Alzheimer's disease protease BACE1 at the synapse in the central nervous system. J. Mol. Neurosci. 60, 305-315. doi: 10.1007/s12031016-0800-1

Nabeka, H., Saito, S., Li, X., Shimokawa, T., Khan, M. S. I., Yamamiya, K., et al. (2017). Interneurons secrete prosaposin, a neurotrophic factor, to attenuate kainic acid-induced neurotoxicity. IBRO Rep. 3, 17-32. doi: 10.1016/j.ibror. 2017.07.001

Nakano, M., Nagaishi, K., Konari, N., Saito, Y., Chikenji, T., Mizue, Y., et al. (2016). Bone marrow-derived mesenchymal stem cells improve diabetesinduced cognitive impairment by exosome transfer into damaged neurons and astrocytes. Sci. Rep. 6:24805. doi: 10.1038/srep24805

Nath, S., Agholme, L., Kurudenkandy, F. R., Granseth, B., Marcusson, J., and Hallbeck, M. (2012). Spreading of neurodegenerative pathology via neuron-to-neuron transmission of $\beta$-amyloid. J. Neurosci. 32, 8767-8777. doi: 10.1523/JNEUROSCI.0615-12.2012

Nguyen, T. M., Arthur, A., Hayball, J. D., and Gronthos, S. (2013). EphB and Ephrin-B interactions mediate human mesenchymal stem cell suppression of activated T-cells. Stem Cells Dev. 22, 2751-2764. doi: 10.1089/scd.2012.0676

Nikitidou, E., Khoonsari, P. E., Shevchenko, G., Ingelsson, M., Kultima, K., and Erlandsson, A. (2017). Increased release of apolipoprotein E in extracellular vesicles following amyloid- $\beta$ protofibril exposure of neuroglial co-cultures. J. Alzheimers Dis. 60, 305-321. doi: 10.3233/jad-170278

Ophelders, D. R., Wolfs, T. G., Jellema, R. K., Zwanenburg, A., Andriessen, P., Delhaas, T., et al. (2016). Mesenchymal stromal cell-derived extracellular vesicles protect the fetal brain after hypoxia-ischemia. Stem Cells Transl. Med. 5, 754-763. doi: 10.5966/sctm.2015-0197

Ostrowski, M., Carmo, N. B., Krumeich, S., Fanget, I., Raposo, G., Savina, A., et al. (2009). Rab27a and Rab27b control different steps of the exosome secretion pathway. Nat. Cell Biol. 12, 19-30. doi: 10.1038/ncb2000

Pham, X., Song, G., Lao, S., Goff, L., Zhu, H., Valle, D., et al. (2016). The DPYSL2 gene connects mTOR and schizophrenia. Transl. Psychiatry 6:e933. doi: 10.1038/tp.2016.204

Phinney, D. G., and Pittenger, M. F. (2017). Concise review: MSC-derived exosomes for cell-free therapy. Stem Cells 35, 851-858. doi: 10.1002/stem.2575

Piper, R. C., and Katzmann, D. J. (2007). Biogenesis and function of multivesicular bodies. Annu. Rev. Cell Dev. Biol. 23, 519-547. doi: 10.1146/annurev.cellbio.23. 090506.123319
Qu, J., and Zhang, H. (2017). Roles of mesenchymal stem cells in spinal cord injury. Stem Cells Int. 2017:5251313. doi: 10.1155/2017/5251313

Rajendran, L., Honsho, M., Zahn, T. R., Keller, P., Geiger, K. D., Verkade, P., et al. (2006). Alzheimer's disease $\beta$-amyloid peptides are released in association with exosomes. Proc. Natl. Acad. Sci. U S A 103, 11172-11177. doi: 10.1073/pnas. 0603838103

Reiman, E. M., Quiroz, Y. T., Fleisher, A. S., Chen, K., Velez-Pardo, C., Jimenez-Del-Rio, M., et al. (2012). Brain imaging and fluid biomarker analysis in young adults at genetic risk for autosomal dominant Alzheimer's disease in the presenilin 1 E280A kindred: a case-control study. Lancet Neurol. 11, 1048-1056. doi: 10.1016/S1474-4422(12) 70228-4

Reiss, A. B., Arain, H. A., Stecker, M. M., Siegart, N. M., and Kasselman, L. J. (2018). Amyloid toxicity in Alzheimer's disease. Rev. Neurosci. 29, 613-627. doi: 10.1515/revneuro-2017-0063

Rodriguez-Grande, B., Varghese, L., Molina-Holgado, F., Rajkovic, O., Garlanda, C., Denes, A., et al. (2015). Pentraxin 3 mediates neurogenesis and angiogenesis after cerebral ischaemia. J. Neuroinflammation 12:15. doi: 10.1186/s12974-014-0227-y

Saman, S., Kim, W., Raya, M., Visnick, Y., Miro, S., Saman, S., et al. (2012). Exosome-associated tau is secreted in tauopathy models and is selectively phosphorylated in cerebrospinal fluid in early Alzheimer disease. J. Biol. Chem. 287, 3842-3849. doi: 10.1074/jbc.M111.277061

Saman, S., Lee, N. C., Inoyo, I., Jin, J., Li, Z., Doyle, T., et al. (2014). Proteins recruited to exosomes by tau overexpression implicate novel cellular mechanisms linking tau secretion with Alzheimer's disease. J. Alzheimers Dis. 40, S47-S70. doi: 10.3233/jad-132135

Scott, C. W., Spreen, R. C., Herman, J. L., Chow, F. P., Davison, M. D., Young, J., et al. (1993). Phosphorylation of recombinant tau by cAMP-dependent protein kinase. Identification of phosphorylation sites and effect on microtubule assembly. J. Biol. Chem. 268, 1166-1173.

Sharples, R. A., Vella, L. J., Nisbet, R. M., Naylor, R., Perez, K., Barnham, K. J., et al. (2008). Inhibition of $\gamma$-secretase causes increased secretion of amyloid precursor protein C-terminal fragments in association with exosomes. FASEB J. 22, 1469-1478. doi: 10.1096/fj.07-9357com

Shi, M., Kovac, A., Korff, A., Cook, T. J., Ginghina, C., Bullock, K. M., et al. (2016). CNS tau efflux via exosomes is likely increased in Parkinson's disease but not in Alzheimer's disease. Alzheimers Dement. 12, 1125-1131. doi: 10.1016/j.jalz. 2016.04 .003

Shibasaki, T., Takahashi, H., Miki, T., Sunaga, Y., Matsumura, K., Yamanaka, M., et al. (2007). Essential role of Epac2/Rap1 signaling in regulation of insulin granule dynamics by cAMP. Proc. Natl. Acad. Sci. U S A 104, 19333-19338. doi: 10.1073/pnas.0707054104

Smith, P. Y., Hernandez-Rapp, J., Jolivette, F., Lecours, C., Bisht, K., Goupil, C., et al. (2015). miR-132/212 deficiency impairs tau metabolism and promotes pathological aggregation in vivo. Hum. Mol. Genet. 24, 6721-6735. doi: $10.1093 / \mathrm{hmg} / \mathrm{ddv} 377$

Spencer, B., Kim, C., Gonzalez, T., Bisquertt, A., Patrick, C., Rockenstein, E., et al. (2016). $\alpha$-Synuclein interferes with the ESCRT-III complex contributing to the pathogenesis of Lewy body disease. Hum. Mol. Genet. 25, 1100-1115. doi: $10.1093 / \mathrm{hmg} / \mathrm{ddv} 633$

Stevanato, L., Thanabalasundaram, L., Vysokov, N., and Sinden, J. D. (2016). Investigation of content, stoichiometry and transfer of miRNA from human neural stem cell line derived exosomes. PLoS One 11:e0146353. doi: 10.1371/journal.pone.0146353

Stoothoff, W. H., and Johnson, G. V. (2005). Tau phosphorylation: physiological and pathological consequences. Biochim. Biophys. Acta 1739, 280-297. doi: 10.1016/j.bbadis.2004.06.017

Stuffers, S., Sem Wegner, C., Stenmark, H., and Brech, A. (2009). Multivesicular endosome biogenesis in the absence of ESCRTs. Traffic 10, 925-937. doi: 10.1111/j.1600-0854.2009.00920.x

Svensson, K. J., Christianson, H. C., Wittrup, A., Bourseau-Guilmain, E., Lindqvist, E., Svensson, L. M., et al. (2013). Exosome uptake depends on ERK1/2-heat shock protein 27 signaling and lipid Raft-mediated endocytosis negatively regulated by caveolin-1. J. Biol. Chem. 288, 17713-17724. doi: 10.1074/jbc.M112.445403

Szklarczyk, D., Morris, J. H., Cook, H., Kuhn, M., Wyder, S., Simonovic, M., et al. (2017). The STRING database in 2017: quality-controlled protein- 
protein association networks, made broadly accessible. Nucleic Acids Res. 45, D362-D368. doi: 10.1093/nar/gkw937

Takahashi, R. H., Milner, T. A., Li, F., Nam, E. E., Edgar, M. A., Yamaguchi, H., et al. (2002). Intraneuronal Alzheimer A $\beta 42$ accumulates in multivesicular bodies and is associated with synaptic pathology. Am. J. Pathol. 161, 1869-1879. doi: 10.1016/s0002-9440(10)64463-X

Tan, J., and Evin, G. (2012). $\beta$-site APP-cleaving enzyme 1 trafficking and Alzheimer's disease pathogenesis. J. Neurochem. 120, 869-880. doi: 10.1111/j. 1471-4159.2011.07623.x

Tang, Y., Bao, J. S., Su, J. H., and Huang, W. (2017). MicroRNA-139 modulates Alzheimer's-associated pathogenesis in SAMP8 mice by targeting cannabinoid receptor type 2. Genet. Mol. Res. 16, 10-4238. doi: 10.4238/gmr160 19166

The UniProt Consortium. (2018). UniProt: the universal protein knowledgebase. Nucleic Acids Res. 46, 2699-2699. doi: 10.1093/nar/gky092

Timmers, L., Lim, S. K., Arslan, F., Armstrong, J. S., Hoefer, I. E., Doevendans, P. A., et al. (2007). Reduction of myocardial infarct size by human mesenchymal stem cell conditioned medium. Stem Cell Res. 1, 129-137. doi: 10.1016/j.scr.2008.02.002

Trajkovic, K., Hsu, C., Chiantia, S., Rajendran, L., Wenzel, D., Wieland, F., et al. (2008). Ceramide triggers budding of exosome vesicles into multivesicular endosomes. Science 319, 1244-1247. doi: 10.1126/science.1153124

Trotta, T., Panaro, M. A., Cianciulli, A., Mori, G., Di Benedetto, A., and Porro, C. (2018). Microglia-derived extracellular vesicles in Alzheimer's disease: a double-edged sword. Biochem. Pharmacol. 148, 184-192. doi: 10.1016/j.bcp. 2017.12.020

Ummenthum, K., Peferoen, L. A., Finardi, A., Baker, D., Pryce, G., Mantovani, A., et al. (2016). Pentraxin-3 is upregulated in the central nervous system during MS and EAE, but does not modulate experimental neurological disease. Eur. J. Immunol. 46, 701-711. doi: 10.1002/eji.201545950

van Hooren, K. W., van Agtmaal, E. L., Fernandez-Borja, M., van Mourik, J. A., Voorberg, J., and Bierings, R. (2012). The Epac-Rap1 signaling pathway controls cAMP-mediated exocytosis of Weibel-Palade bodies in endothelial cells. J. Biol. Chem. 287, 24713-24720. doi: 10.1074/jbc.M111.321976

Vella, L. J., Sharples, R. A., Nisbet, R. M., Cappai, R., and Hill, A. F. (2008). The role of exosomes in the processing of proteins associated with neurodegenerative diseases. Eur. Biophys. J. 37, 323-332. doi: 10.1007/s00249-007-0246-z

Vilar, M., and Mira, H. (2016). Regulation of neurogenesis by neurotrophins during adulthood: expected and unexpected roles. Front. Neurosci. 10:26. doi: 10.3389/fnins.2016.00026

Villarroya-Beltri, C., Gutiérrez-Vázquez, C., Sánchez-Cabo, F., PérezHernández, D., Vázquez, J., Martin-Cofreces, N., et al. (2013). Sumoylated hnRNPA2B1 controls the sorting of miRNAs into exosomes through binding to specific motifs. Nat. Commun. 4:2980. doi: 10.1038/ncomms3980

Vingtdeux, V., Sergeant, N., and Buee, L. (2012). Potential contribution of exosomes to the prion-like propagation of lesions in Alzheimer's disease. Front. Physiol. 3:229. doi: 10.3389/fphys.2012.00229

Wakabayashi, T., Craessaerts, K., Bammens, L., Bentahir, M., Borgions, F., Herdewijn, P., et al. (2009). Analysis of the $\gamma$-secretase interactome and validation of its association with tetraspanin-enriched microdomains. Nat. Cell Biol. 11, 1340-1346. doi: 10.1038/ncb1978

Wang, F., Baba, N., Shen, Y., Yamashita, T., Tsuru, E., Tsuda, M., et al. (2017). CCL11 promotes migration and proliferation of mouse neural progenitor cells. Stem Cell Res. Ther. 8:26. doi: 10.1186/s13287-017-0474-9

Wang, Y., Balaji, V., Kaniyappan, S., Krüger, L., Irsen, S., Tepper, K., et al. (2017). The release and trans-synaptic transmission of Tau via exosomes. Mol. Neurodegener. 12:5. doi: 10.1186/s13024-016-0143-y

Wang, G., Dinkins, M., He, Q., Zhu, G., Poirier, C., Campbell, A., et al. (2012). Astrocytes secrete exosomes enriched with proapoptotic ceramide and prostate apoptosis response 4 (PAR-4): potential mechanism of apoptosis induction in Alzheimer disease (AD). J. Biol. Chem. 287, 21384-21395. doi: 10.1074/jbc. M112.340513

Wang, X., Dong, C., Sun, L., Zhu, L., Sun, C., Ma, R., et al. (2016). Quantitative proteomic analysis of age-related subventricular zone proteins associated with neurodegenerative disease. Sci. Rep. 6:37443. doi: 10.1038/srep37443

Wei, X., Yang, X., Han, Z. P., Qu, F. F., Shao, L., and Shi, Y. F. (2013). Mesenchymal stem cells: a new trend for cell therapy. Acta Pharmacol. Sin. 34, 747-754. doi: 10.1038/aps. 2013.50
Wilkinson, D. G. (2001). Multiple roles of EPH receptors and ephrins in neural development. Nat. Rev. Neurosci. 2, 155-164. doi: 10.1038/35 058515

Wischik, C. M., Crowther, R. A., Stewart, M., and Roth, M. (1985). Subunit structure of paired helical filaments in Alzheimer's disease. J. Cell Biol. 100, 1905-1912. doi: 10.1083/jcb.100.6.1905

Wischik, C. M., Novak, M., Edwards, P. C., Klug, A., Tichelaar, W., and Crowther, R. A. (1988). Structural characterization of the core of the paired helical filament of Alzheimer disease. Proc. Natl. Acad. Sci. U S A 85, 4884-4888. doi: 10.1073/pnas.85.13.4884

Wu, Y., Deng, W., and Klinke, D. J. II. (2015). Exosomes: improved methods to characterize their morphology, RNA content, and surface protein biomarkers. Analyst 140, 6631-6642. doi: 10.1039/c5an00688k

Xiao, T., Zhang, W., Jiao, B., Pan, C. Z., Liu, X., and Shen, L. (2017). The role of exosomes in the pathogenesis of Alzheimer' disease. Transl. Neurodegener. 6:3. doi: 10.1186/s40035-017-0072-x

Xin, H., Katakowski, M., Wang, F., Qian, J. Y., Liu, X. S., Ali, M. M., et al. (2017a). MicroRNA cluster miR-17-92 cluster in exosomes enhance neuroplasticity and functional recovery after stroke in rats. Stroke 48, 747-753. doi: 10.1161/STROKEAHA.116.015204

Xin, H., Wang, F., Li, Y., Lu, Q. E., Cheung, W. L., Zhang, Y., et al. (2017b). Secondary release of exosomes from astrocytes contributes to the increase in neural plasticity and improvement of functional recovery after stroke in rats treated with exosomes harvested from MicroRNA 133b-overexpressing multipotent mesenchymal stromal cells. Cell Transplant. 26, 243-257. doi: 10.3727/096368916x693031

Xin, H., Li, Y., Cui, Y., Yang, J. J., Zhang, Z. G., and Chopp, M. (2013a). Systemic administration of exosomes released from mesenchymal stromal cells promote functional recovery and neurovascular plasticity after stroke in rats. J. Cereb. Blood Flow Metab. 33, 1711-1715. doi: 10.1038/jcbfm.2013.152

Xin, H., Li, Y., Liu, Z., Wang, X., Shang, X., Cui, Y., et al. (2013b). MiR$133 \mathrm{~b}$ promotes neural plasticity and functional recovery after treatment of stroke with multipotent mesenchymal stromal cells in rats via transfer of exosome-enriched extracellular particles. Stem Cells 31, 2737-2746. doi: 10.1002/stem.1409

Xiong, Y., Mahmood, A., and Chopp, M. (2017). Emerging potential of exosomes for treatment of traumatic brain injury. Neural Regen. Res. 12, 19-22. doi: 10.4103/1673-5374.198966

Yan, R., Fan, Q., Zhou, J., and Vassar, R. (2016). Inhibiting BACE1 to reverse synaptic dysfunctions in Alzheimer's disease. Neurosci. Biobehav. Rev. 65, 326-340. doi: 10.1016/j.neubiorev.2016.03.025

Yang, Y., Ye, Y., Su, X., He, J., Bai, W., and He, X. (2017). MSCs-derived exosomes and neuroinflammation, neurogenesis and therapy of traumatic brain injury. Front. Cell. Neurosci. 11:55. doi: 10.3389/fncel.2017.00055

Yang, J., Zhang, X., Chen, X., Wang, L., and Yang, G. (2017). Exosome mediated delivery of miR-124 promotes neurogenesis after ischemia. Mol. Ther. Nucleic Acids 7, 278-287. doi: 10.1016/j.omtn.2017.04.010

Yin, Z. S., Zhang, H., Wang, W., Hua, X. Y., Hu, Y., Zhang, S. Q., et al. (2007). Wnt-3a protein promote neuronal differentiation of neural stem cells derived from adult mouse spinal cord. Neurol. Res. 29, 847-854. doi: $10.1179 / 016164107 \times 223539$

Yuyama, K., and Igarashi, Y. (2017). Exosomes as carriers of Alzheimer's amyloidB. Front. Neurosci. 11:229. doi: 10.3389/fnins.2017.00229

Zappulli, V., Friis, K. P., Fitzpatrick, Z., Maguire, C. A., and Breakefield, X. O. (2016). Extracellular vesicles and intercellular communication within the nervous system. J. Clin. Invest. 126, 1198-1207. doi: 10.1172/jci81134

Zhang, Z. G., and Chopp, M. (2015). Promoting brain remodeling to aid in stroke recovery. Trends Mol. Med. 21, 543-548. doi: 10.1016/j.molmed.2015. 07.005

Zhang, Y., Chopp, M., Zhang, Z. G., Katakowski, M., Xin, H., Qu, C., et al. (2017). Systemic administration of cell-free exosomes generated by human bone marrow derived mesenchymal stem cells cultured under 2D and $3 \mathrm{D}$ conditions improves functional recovery in rats after traumatic brain injury. Neurochem. Int. 111, 69-81. doi: 10.1016/j.neuint.2016. 08.003

Zhang, J., Li, S., Li, L., Li, M., Guo, C., Yao, J., et al. (2015). Exosome and exosomal microRNA: trafficking, sorting, and function. Genomics Proteomics Bioinformatics 13, 17-24. doi: 10.1016/j.gpb.2015.02.001 
Zhang, Y.-L., Wang, R.-C., Cheng, K., Ring, B. Z., and Su, L. (2017). Roles of Rap1 signaling in tumor cell migration and invasion. Cancer Biol. Med. 14, 90-99. doi: 10.20892/j.issn.2095-3941.2016.0086

Zhang, G., and Yang, P. (2018). A novel cell-cell communication mechanism in the nervous system: exosomes. J. Neurosci. Res. 96, 45-52. doi: 10.1002/jnr.24113

Zhao, Y., Gibb, S. L., Zhao, J., Moore, A. N., Hylin, M. J., Menge, T., et al. (2016a). $\mathrm{Wnt} 3 \mathrm{a}$, a protein secreted by mesenchymal stem cells is neuroprotective and promotes neurocognitive recovery following traumatic brain injury. Stem Cells 34, 1263-1272. doi: 10.1002/stem.2310

Zhao, Y., Tan, W., Sheng, W., and Li, X. (2016b). Identification of biomarkers associated With Alzheimer's disease by bioinformatics analysis. Am. J. Alzheimers Dis. Other Demen. 31, 163-168. doi: 10.1177/15333175155 88181

Zheng, T., Pu, J., Chen, Y., Mao, Y., Guo, Z., Pan, H., et al. (2017). Plasma exosomes spread and cluster around $\beta$-amyloid plaques in an animal model of Alzheimer's disease. Front. Aging. Neurosci. 9:12. doi: 10.3389/fnagi.2017.00012
Zmuda, J. F., and Rivas, R. J. (2000). Actin disruption alters the localization of tau in the growth cones of cerebellar granule neurons. J. Cell Sci. 113, 2797-2809. doi: 10.1002/1097-4695(20000615)43:4<313::aid-neu1>3.0.co;2-2

Conflict of Interest Statement: The authors declare that the research was conducted in the absence of any commercial or financial relationships that could be construed as a potential conflict of interest.

Copyright (C) 2018 Reza-Zaldivar, Hernández-Sapiéns, Minjarez, GutiérrezMercado, Márquez-Aguirre and Canales-Aguirre. This is an open-access article distributed under the terms of the Creative Commons Attribution License (CC BY). The use, distribution or reproduction in other forums is permitted, provided the original author(s) and the copyright owner(s) are credited and that the original publication in this journal is cited, in accordance with accepted academic practice. No use, distribution or reproduction is permitted which does not comply with these terms. 